\title{
Sucesión volcánica Jurásica en el área de Charcas, San Luis Potosí: Contribución al entendimiento del Arco Nazas en el noreste de México
}

\author{
Aurora Zavala-Monsiváis ${ }^{1, *}$, José Rafael Barboza-Gudiño ${ }^{2}$, Fernando Velasco-Tapia ${ }^{3}$, \\ María Elena García-Arreola ${ }^{2}$ \\ ${ }^{1}$ Posgrado en Geociencias, Facultad de Ciencias de la Tierra, Universidad Autónoma de Nuevo León.Carretera a Cerro Prieto Km 8, \\ Ex-hacienda de Guadalupe, Linares, N.L., México, C.P. 67700. \\ ${ }^{2}$ Instituto de Geología, Universidad Autónoma de San Luis Potosí. Av. Manuel Nava No. 5, Zona Universitaria, San Luis Potosí, \\ S.L.P., México, C.P. 78240. \\ ${ }^{3}$ Facultad de Ciencias de la Tierra,Universidad Autónoma de Nuevo León.Carretera a Cerro Prieto Km 8, Ex-hacienda de Guadalupe, \\ Linares, N.L., México, C.P. 67700 \\ *monaurora.z@gmail.com
}

\begin{abstract}
Resumen
El presente trabajo reporta datos de campo, petrográficos, geoquímicos y geocronológicos de U-Pb en circones de una sucesión volcánica de decenas a cientos de metros de espesor, que sobreyace de manera discordante a sedimentos triásicos marinos de la Formación Zacatecas y subyace en discordancia erosional a los depósitos clásticos de la Formación La Joya, del Calloviano-Oxfordiano, al poniente de Charcas, San Luis Potosí. Esta sucesión volcánica ha sido correlacionada por semejanza litológica y posición estratigráfica con pequeños afloramientos de rocas comparables, distribuidos desde el norte, de los estados de Durango y Zacatecas y sur de Coahuila, hasta el sur de Nuevo León, Tamaulipas y el poniente del estado de San Luis Potosí. Las rocas estudiadas corresponden geoquímicamente a andesitas, dacitas y riolitas, y muestran un amplio rango composicional $\left(\mathrm{SiO}_{2}=53-82 \%\right)$. La geoquímica de elementos traza se empleó para determinar el ambiente tectónico, y se encontró que los diagramas de elementos de tierras raras se caracterizan por enriquecimientos en las tierras raras ligeras con una pequeña anomalía negativa en Eu, mientras que los diagramas multielementos presentan patrones con enriquecimiento en elementos litófilos de ión grande (LILE, large ion lithophile elements), con una clara anomalía negativa en $\mathrm{Nb}$ y Ta. De igual manera los diagramas de discriminación tectonomagmática muestran un ambiente tectónico de arco volcánico. Se reporta además la primera datación isotópica para esta localidad, resultado del análisis de U-Pb en 29 circones por la técnica de ablación laser en un equipo ICP-MS con multicolector, la cual arrojó una edad de 179 Ma para un flujo piroclástico de composición riodacítica. La interpretación de estos datos sustenta la correlación de esta sucesión volcánica, tanto en su ambiente geotectónico como en el tiempo, con las rocas expuestas en otras localidades del arco volcánico continental del Jurásico Inferior en el noreste de México. Dichas rocas han sido consideradas como parte del arco volcánico continental del Jurásico Inferior situado a lo largo de la paleomargen pacífica de Pangea.
\end{abstract}

Palabras clave: Jurásico, arco volcánico, Mesa Central, geoquímica, geocronología.

\section{Abstract}

This paper reports field, petrographic, geochemical and zircon U-Pb geochronological data for a volcanic succession several tens to hundreds of meters thick, unconformably overlying Triassic marine sediments of the Zacatecas Formation and covered in erosional unconformity by clastic deposits of La Joya Formation of Callovian-Oxfordian age, west of Charcas, San Luis Potosi. This volcanic succession has been correlated by lithological similarity and stratigraphic position with small comparable outcrops, distributed from the northern states of Durango, Zacatecas and southern Coahuila, to southern Nuevo Leon, Tamaulipas, and the western part of the 
state of San Luis Potosí. The studied rocks correspond geochemically to andesites, dacites and rhyolites, showing a wide compositional range $\left(\mathrm{SiO}_{2}=53-82 \%\right)$. Trace element geochemistry was used to determine the tectonic setting, with rare earth element diagrams chacterized by enrichments in light rare earth elements and a small negative Eu anomaly, while multi-element diagrams show large ion lithophile element (LILE) enrichment, with a clear negative anomaly in Nb and Ta. Similarly, tectonomagmatic discrimination diagrams indicate a volcanic arc tectonic environment. We report the first isotopic dating for this locality, from the U-Pb analysis of 29 zircons with laser ablation multi-collector ICP-MS, which yielded an age of $179 \mathrm{Ma}$ for a rhyodacitic pyroclastic flow. The interpretation of these data supports the correlation of this volcanic succession, in both geotectonic setting and age, with rocks exposed in other localities of the Lower Jurassic continental volcanic arc in northeastern Mexico. These rocks have been considered part of the Lower Jurassic continental volcanic arc located along the paleo-Pacific margin of Pangea.

Keywords: Jurassic, volcanic arc, Mesa Central, geochemistry, geochronology.

\section{Introducción}

A $130 \mathrm{~km}$ al noroeste de San Luis Potosí, San Luis Potosí, en la porción centro-sur de la Mesa Central, se ubica la Sierra de Charcas (Figura 1). Esta sierra se conformó como resultado del desarrollo del Anticlinorio de San Rafael-La Trinidad, una estructura más o menos elíptica con una orientación NE-SW(Figura 2).En el núcleo del anticlinorio aflora la unidad estratigráfica más antigua de la Mesa Central, la cual corresponde a los sedimentos siliciclásticos marinos de la Formación Zacatecas (Triásico Superior; Martínez-Pérez, 1972). Éstos son cubiertos por una secuencia volcánica y volcanoclástica que representa el objeto de este trabajo y que fue estudiada inicialmente en esta área por Tristán-González y Torres-Hernández (1991, 1992, 1994). Dichos autores, a partir de su litología y su posición estratigráfica, la correlacionaron con la Formación Nazas, descrita originalmente por PantojaAlor (1972), quien le asignó una edad del Triásico TardíoJurásico Temprano en el área de Villa Juárez, Durango. Afloramientos de rocas similares se distribuyen en varias localidades del centro-noreste de México (Figura 1). Esta sucesión es cubierta de forma discordante por las capas rojas de la Formación La Joya, aunque en algunas localidades es sobreyacida directamente por una secuencia carbonatada del Jurásico Superior (Formación Zuloaga), la cual aflora en las partes altas del Anticlinorio San Rafael-La Trinidad.

Por otra parte, estudios previos indican que las sucesiones volcánicas y volcanoclásticas que sobreyacen a las rocas triásicas, o en algunos casos a unidades más antiguas, presentan características geoquímicas típicas de magmas de arco continental (Bartolini, 1998; Bartolini et al., 1999; Jones et al., 1995; Gómez-Anguiano, 2001; Fastowsky et al., 2005; Barboza-Gudiño et al., 2008). Bartolini et al. (2003) establecieron que las rocas volcanoclásticas y volcánicas de la Formación Nazas pertenecen al arco volcánico del Triásico Superior al Jurásico Medio, relacionado a la margen continental activa del oeste de México o "Arco Nazas". Sin embargo, Barboza-Gudiño et al. (1998, 1999, 2008) consideraron a la Formación Nazas como un volcanismo jurásico establecido a lo largo de la margen continental activa del oeste de Norte América y enfatizan que la edad del volcanismo de este arco se restringe sólo al Jurásico Inferior a Medio.

Dada la importancia que estas rocas representan para el entendimiento de la paleogeografía de la margen occidental de Pangea, nuestro objetivo ha sido la descripción detallada de la sucesión volcánica en el área de estudio, reportando nuevos análisis petrográficos y geoquímicos, así como datos geocronológicos de $\mathrm{U}-\mathrm{Pb}$ en circones, que apoyen su correlación con otros afloramientos del noreste de México y contribuyan a sustentar la presencia del magmatismo del Arco Nazas en la parte centro-sur de la Mesa Central.

\section{Estratigrafía Regional del Mesozoico temprano}

El área de interés se encuentra ubicada en el borde oriental de la Cuenca Mesozoica del Centro de México (Figura 1). En los siguientes apartados se describen las características litológicas que distinguen a las unidades estratigráficas triásicas y jurásicas que subyacen y sobreyacen, respectivamente, a la sucesión volcánica en la zona de Charcas, San Luis Potosí.

\subsection{Formación Zacatecas (Triásico Superior)}

Esta unidad representa una sucesión siliciclástica turbidítica constituida por una alternancia rítmica de arenisca, predominantemente de grano medio a fino $\mathrm{y}$ ocasionalmente conglomerática, de color gris oscuro, que intemperiza en tonalidades café rojizo a amarillento, con intercalaciones de lutitas de color gris verdoso a oscuro (Martínez-Pérez, 1972). Estas capas fueron depositadas en un ambiente de abanico submarino dentro de un miogeoclinal en la margen paleopacífica de Pangea (SilvaRomo et al., 2000; Hoppe et al., 2002; Barboza-Gudiño et al., 1999, 2010) con contenido de fauna de amonoideos del Cárnico inferior (Cantú-Chapa, 1969) y conodontos (Cuevas-Pérez, 1985).

En el área de Charcas se observa una predominancia de capas a bancos de areniscas finas, y ocasionalmente gruesas, 


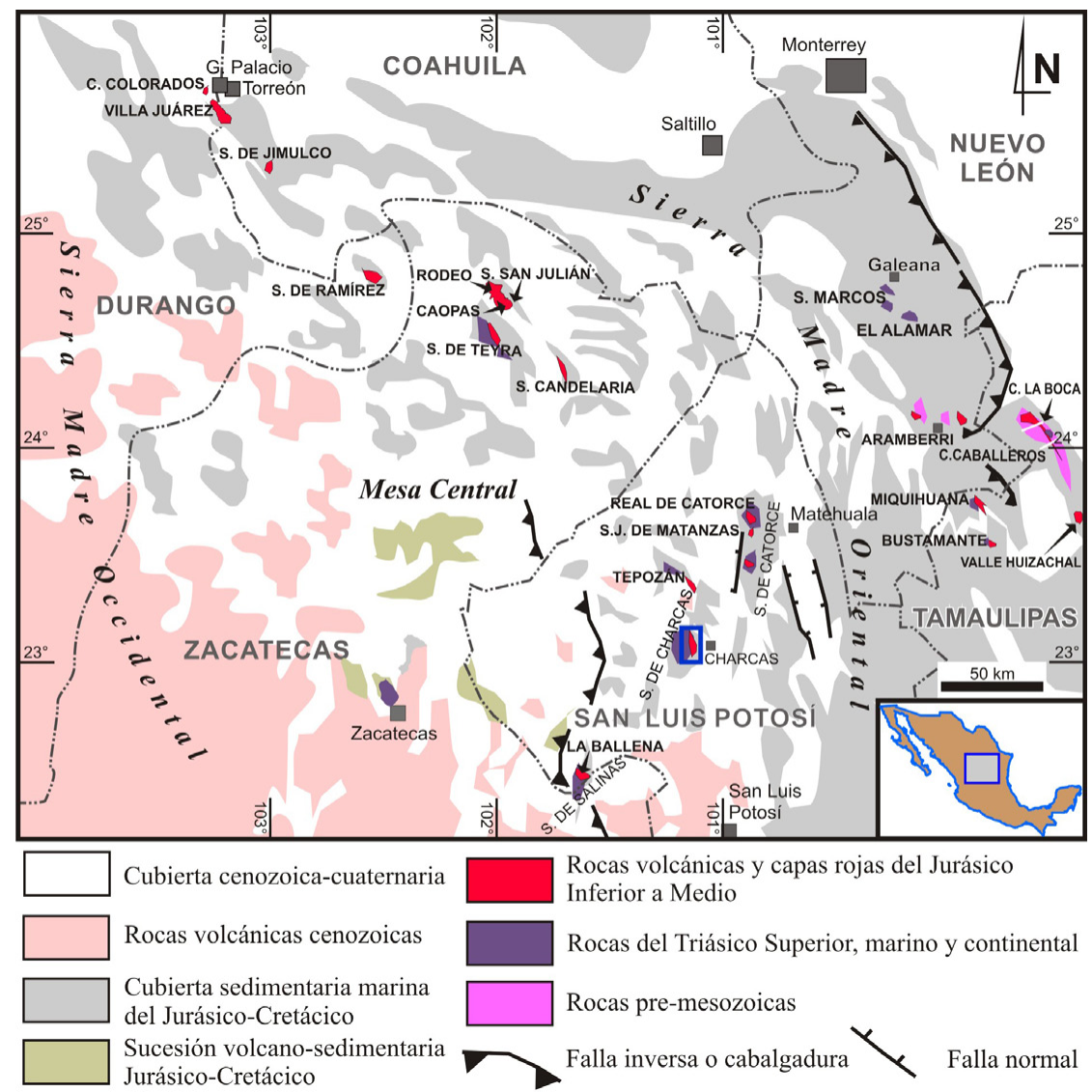

Figura 1. Localidades con afloramientos de rocas volcánicas del Jurásico Inferior a Medio en el centro-noreste de México (modificado de Barboza-Gudiño et al., 1999) y localización del área de estudio (recuadro azul).

hasta conglomeráticas, de color gris oscuro que intemperizan en gris claro a verdoso y amarillo ocre, alternando con lutitas de color negro que también intemperizan en gris claro amarillento. Estas secuencias de carácter turbidítico presentan, en la mayoría de los casos, sólo parcialmente secuencias tipo Bouma y exhiben en general las diferentes facies descritas por Mutti y Ricci-Lucchi (1972) para depósitos de abanicos submarinos (Barboza-Gudiño et al., 2010). En algunos afloramientos se observan estructuras como plegamientos sinsedimentarios y bloques deslizados de la misma secuencia, aparentemente como resultado de caídos en pendientes o márgenes de taludes y canales.

El espesor de esta formación no se ha podido establecer con precisión en toda la Mesa Central, ya que en ninguna localidad aflora su base. En el área de Charcas ocurren afloramientos extensos pero, dada la intensa deformación, los máximos espesores que se pueden apreciar posiblemente no rebasan los $500 \mathrm{~m}$.

\subsection{Formación Nazas (Jurásico Inferior a Medio)}

Sobreyaciendo de manera discordante a la Formación Zacatecas se encuentra una sucesión de rocas volcanogénicas constituida por flujos piroclásticos, flujos de lava, brechas $\mathrm{y}$ tobas de grano fino. Esta unidad, a nivel regional, se ha denominado Formación Nazas (Pantoja-Alor, 1972; Jones et al., 1995; Barboza-Gudiño et al., 1998, 1999, 2008; Bartolini, 1998; Bartolini et al., 2003) y es motivo del presente estudio, por lo que se hará una descripción más detallada en los siguientes apartados. Su espesor es muy variable, desde los puntos en que está ausente por no depósito hasta algunas secciones en donde varía de $20 \mathrm{~m}$ a $200 \mathrm{~m}$.

\subsection{Formación La Joya (Jurásico Medio-Superior)}

La Formación Nazas, y la Formación Zacatecas cuando la primera está ausente, son sobreyacidas en discordancia angular por la Formación La Joya (Calloviano-Oxfordiano; Mixon, 1963). La Formación La Joya, en el área de Charcas se encuentra constituida en su base por un conglomerado y/o una brecha de materiales retrabajados, en su mayoría procedentes de productos volcánicos. En su parte media presenta una alternancia de capas de arenisca de grano medio a fino, que hacia la cima gradúan hacia limolitas y lutitas de color rojo. En algunos casos, parte de la secuencia ya presenta indicios de una sedimentación marina somera. El espesor que alcanza esta unidad es entre $150 \mathrm{~m}$ y 200 $\mathrm{m}$, siendo muy variable y llegando incluso a faltar por completo, aparentemente por no depósito, en algunos 


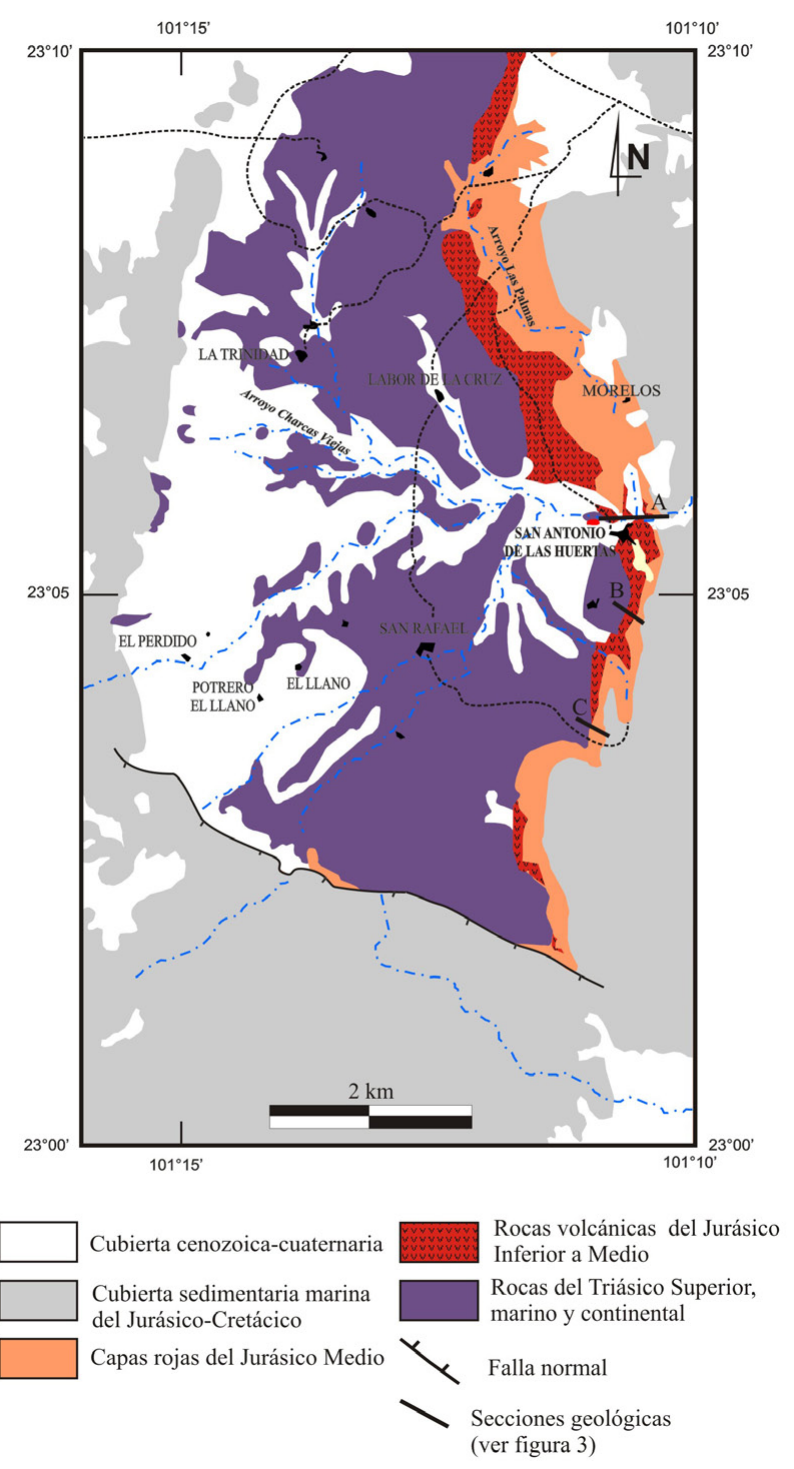

Figura 2. Mapa geológico de la Sierra de Charcas y ubicación de las secciones medidas (modificado de Barboza-Gudiño et al., 2010).

puntos. Regionalmente pasa en su cima, de manera transicional, a calizas de la Formación Zuloaga.

\subsection{Formación Zuloaga (Jurásico Superior)}

La Formación Zuloaga (Oxfordiano-Kimmeridgiano; Burckhardt, 1930; Imlay, 1936) sobreyace de manera concordante y ligeramente transicional a la Formación La Joya. Representa, de manera general, la base de la transgresión marina que en el Jurásico Superior inundó la porción oriental del territorio mexicano procedente del este, como resultado de la apertura del Golfo de México. Está formada por calizas de color gris oscuro, en capas gruesas a bancos, con gasterópodos, pelecípodos y corales hacia la cima. Su espesor a nivel regional es variable, entre $80 \mathrm{~m}$ y $100 \mathrm{~m}$, alcanzando en algunos afloramientos $\operatorname{los} 200 \mathrm{~m}$. Se encuentra sobreyacida por toda la sucesión de sedimentos clásticos y carbonatados del Jurásico Superior y Cretácico, pertenecientes a la denominada Cuenca Mesozoica del Centro de México (Carrillo-Bravo, 1971).

\section{La sucesión volcánica jurásica del área de Charcas}

En el área de estudio, las rocas volcánicas consideradas como parte de la Formación Nazas se restringen a la parte interna de la margen oriental del Anticlinorio La TrinidadSan Rafael, ubicado al SW de Charcas, San Luis Potosí. En esta zona se midieron a detalle tres columnas estratigráficas: (A) a lo largo del lecho del arroyo San Antonio; (B) al sur de la comunidad de San Antonio de las Huertas, sobre el Cerro La Medalla o La Sancheña; y (C) sobre el camino a la localidad de La Medalla, al sur del Cerro Buenavista. La ubicación de las tres secciones medidas para la reconstrucción de las columnas se señala en la Figura 2. La Figura 3 muestra las secciones levantadas, y en la Figura 4 se presentan las columnas estratigráficas correspondientes, permitiendo su correlación. En las secciones levantadas se incluye la descripción de parte de las unidades subyacentes y sobreyacentes a la sucesión de rocas volcánicas, objeto del presente trabajo, con el fin de visualizar mejor sus relaciones estratigráficas; ya que, en algunos casos (especialmente en la Formación La Joya), su límite con las rocas volcánicas es difícil de establecer, por la ocurrencia de materiales epiclásticos intercalados en la sucesión volcánica, los cuales son muy similares en su aspecto a los materiales retrabajados que son más propiamente depósitos sedimentarios de la Formación La Joya.

\subsection{Sección Arroyo San Antonio (A)}

La sección fue medida en una dirección $\mathrm{N} 70^{\circ} \mathrm{E}$ partiendo de las coordenadas $23^{\circ} 5.727^{\prime} \mathrm{N}, 101^{\circ} 10.795^{\prime}$ W, sobre el límite por falla entre la Formación Zacatecas y la Formación Nazas, hasta las coordenadas $23^{\circ} 5.711^{\prime}$ N, $101^{\circ} 10.782^{\prime} \mathrm{W}$ como punto final. En esta localidad la Formación Zacatecas se observa muy deformada y consiste de lutitas de color negro y areniscas finas a limolitas de color gris intermedio que intemperizan en gris claro y amarillo ocre. La falla que separa a ambas unidades se observa sólo en un afloramiento muy reducido en el lecho del arroyo y en gran medida está cubierta por materiales aluviales. Sin embargo, su desplazamiento se puede identificar como de tipo normal, posiblemente con una componente lateral izquierda, con rumbo general entre $\mathrm{N} 10^{\circ} \mathrm{W}$ y N $15^{\circ} \mathrm{W}$. A lo largo de esta sección, aunque se tienen buenos afloramientos de varios paquetes de rocas volcánicas, estos se interrumpen frecuentemente por la cobertura de aluvión. Por esta razón, la relación estratigráfica entre las unidades litológicas es incierta y el perfil estratigráfico presenta frecuentes interrupciones. El motivo por el cual se ha incluido esta sección, es la presencia de unidades litológicas y estructuras que en otros afloramientos no se observan con la misma 
Arroyo San Antonio

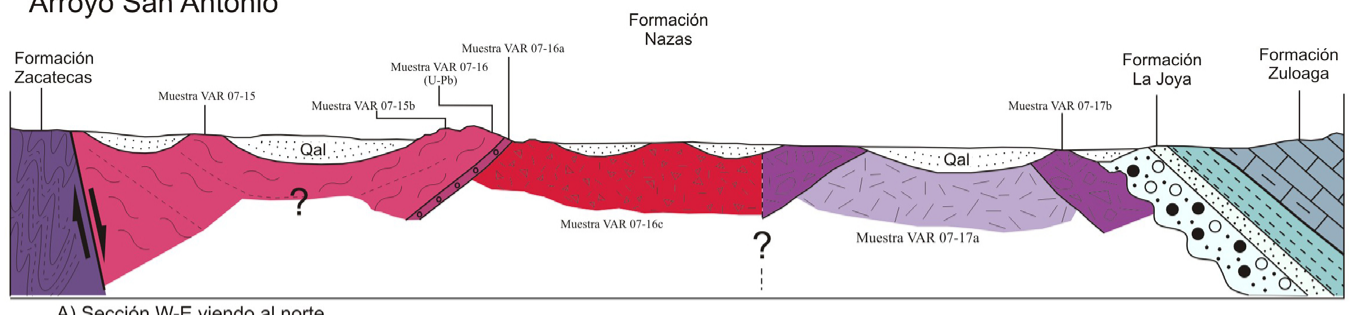

A) Sección W-E viendo al norte

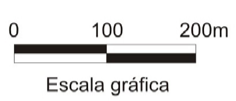

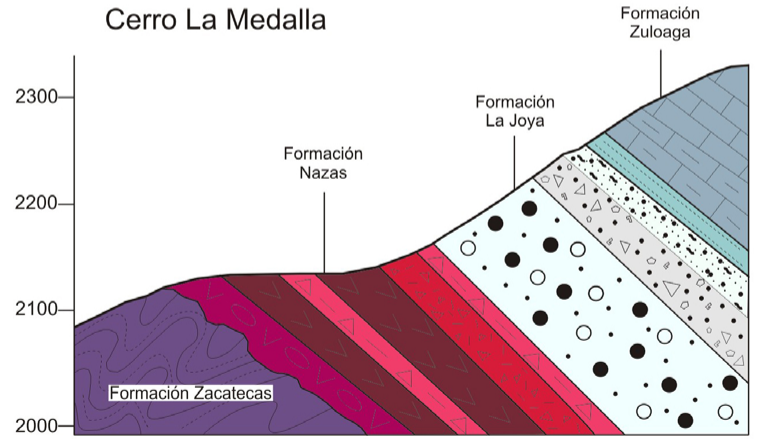

B) Sección NW-SE viendo al norte

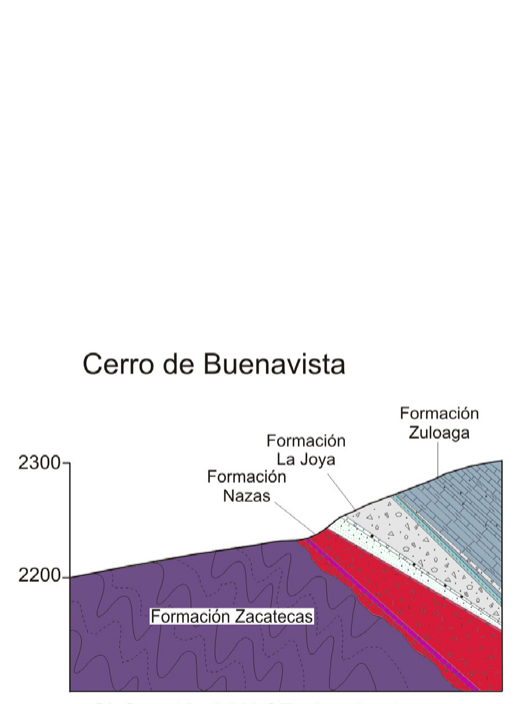

C) Sección NW-SE viendo al norte

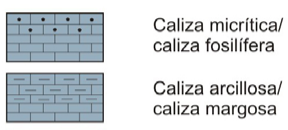

Limolita

Arenisca/arenisca conglomerática

Conglomerado polimíctico

Brecha polimíctica

Brecha volcánica

Depósito epiclástico

Ignimbrita

Flujo piroclástico riolítico/riodacítico

Flujo piroclástico dacitico/andesítico

Vitrófido

Brecha volcánica de desintegración

Lava andesítica

Formación Zacatecas

Figura 3. Secciones medidas en el área de estudio. Se puede observar la variación en el espesor y la litología de la secuencia volcánica jurásica: (A) sobre el lecho del arroyo San Antonio; (B) ladera poniente del cerro La Medalla; y (C) sobre el camino que va de San Rafael hacia La Medalla, en el cerro de Buenavista (ver Figura 2 para localización de las secciones).

calidad, habiéndose colectado aquí las muestras para los estudios geoquímicos y geocronológicos.

La base de la sucesión volcánica está constituida por 30 $\mathrm{m}$ de una secuencia de flujos piroclásticos muy alterados e intemperizados, la cual se interrumpe por $\sim 50 \mathrm{~m}$ y continúa en forma de flujo piroclástico brechoide de composición intermedia a félsica, con abundantes fragmentos angulosos de rocas volcánicas (diámetro $=5 \mathrm{~mm}$ a $30 \mathrm{~mm}$ ), así como algunas litofisas aisladas de hasta $10 \mathrm{~cm}$ de diámetro (Figura 5A). La matriz del flujo está compuesta de cenizas o material fino con sericitización en agregados con formas sigmoidales pobremente desarrolladas o a lo largo de superficies de clivaje o foliación (Figura 5B). Los fragmentos de roca muestran regularmente textura traquítica $\mathrm{y}$, en algunos casos, fenocristales aislados de plagioclasa con alteración hacia sericita y óxidos.

Sobre el primer flujo descansa una roca desvitrificada muy alterada de color claro amarillento a crema, con esferulitas de hasta $2 \mathrm{~cm}$ de diámetro deformadas por efecto del cizallamiento a lo largo de superficies de foliación. Al microscopio, en la roca desvitrificada se observan también estructuras esferulíticas del orden de $1 \mathrm{~mm}$ o menores. Este horizonte, de $1 \mathrm{~m}$ a $1.5 \mathrm{~m}$ de espesor, gradúa hacia arriba a un flujo piroclástico de color café rojizo que muestra un bandeamiento incipiente de flujo, con menor cantidad de esferulitas y esporádicos fragmentos subangulosos de rocas volcánicas intermedias a félsicas, así como fragmentos de pómez, en parte colapsada, mostrando estructuras tipo fiame (Figura 5C).

Después de una nueva interrupción, en donde los afloramientos quedan cubiertos por material aluvial, aparece un flujo de lava de color gris oscuro con fenocristales de plagioclasa, en matriz criptocristalina a microcristalina con abundante carbonato reemplazando a los fenocristales $\mathrm{y}$ entre los intersticios minerales (Figura 5D). Este flujo se observa intercalado con una brecha volcánica compacta con fragmentos angulosos y subangulosos de $1 \mathrm{~cm}$ a $30 \mathrm{~cm}$ de diámetro con estructura de rompecabezas (Figura 5E). Los fragmentos son de la misma composición que el flujo lávico (Figura 5F) y están englobados en un sedimento rico en carbonatos, por lo que parte de estas rocas se han interpretado tentativamente como peperitas. 


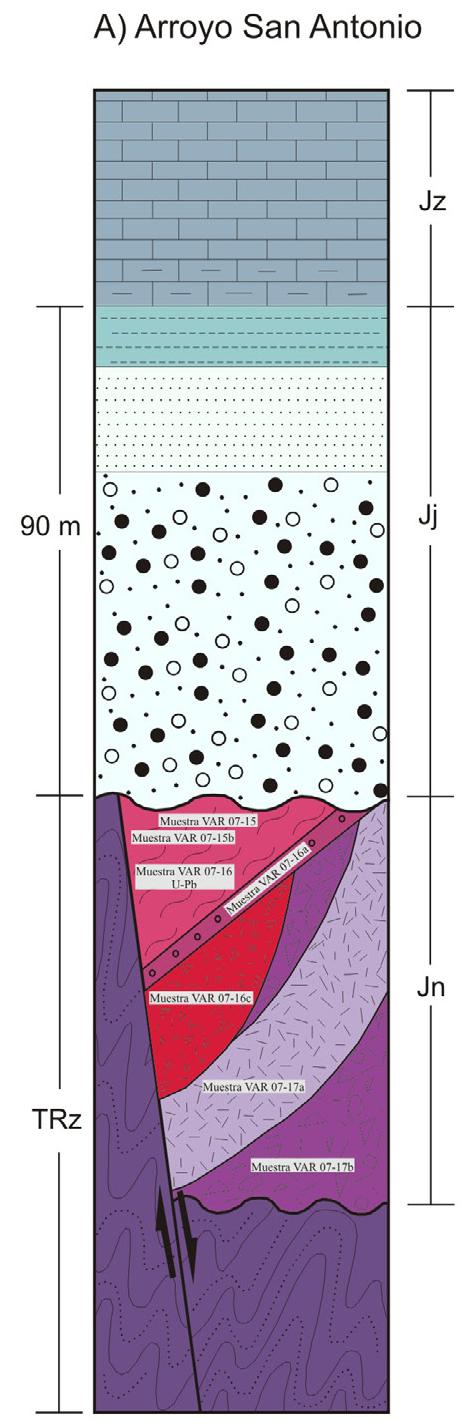

\section{B) Cerro La Medalla}

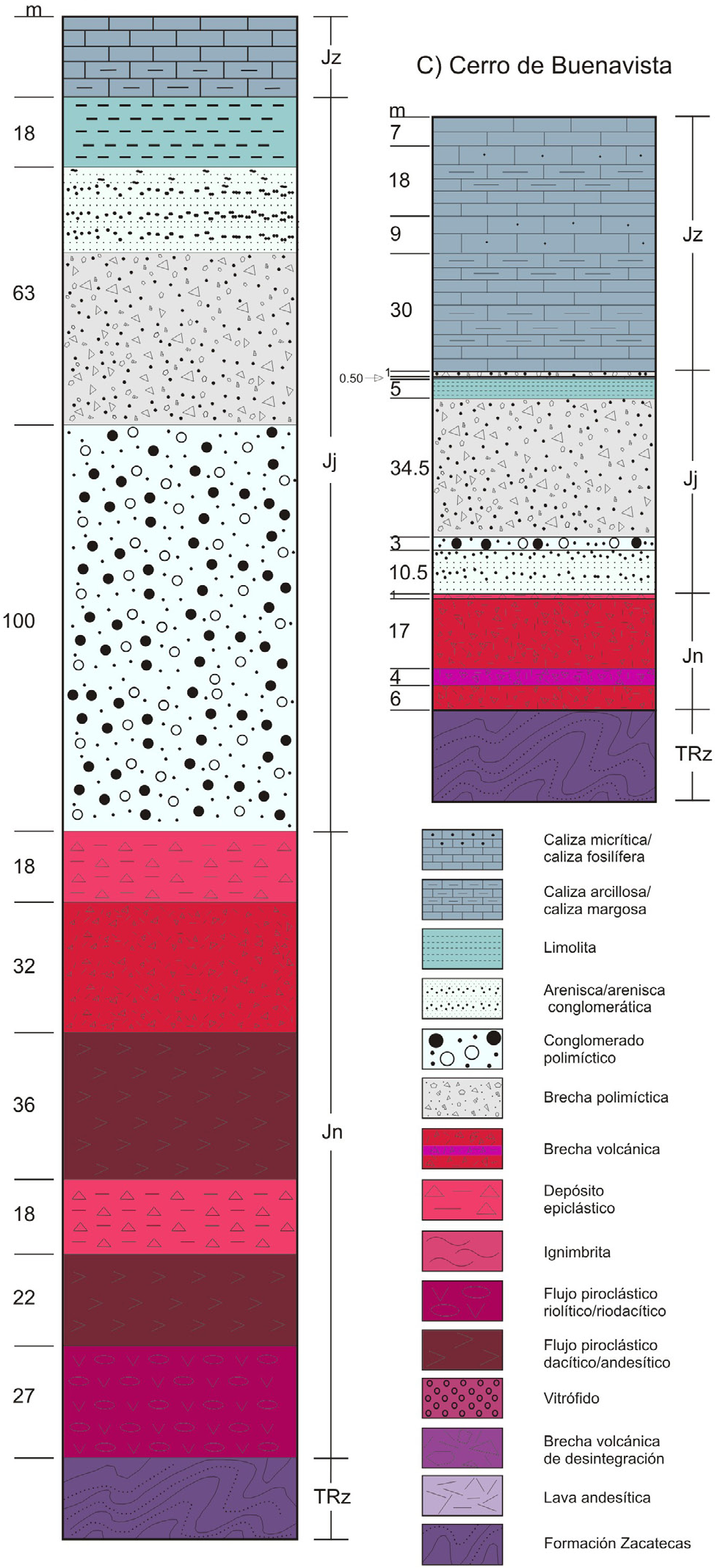

Figura 4.Columnas estratigráficas realizadas a partir de las secciones descritas en el texto. En ellas se puede observar la correlación que existe en las unidades litológicas que componen la sucesión volcánica en cada localidad. Abreviaturas: TRz $=$ Formación Zacatecas, Jn $=$ Formación Nazas, Jj $=$ Formación La Joya, Jz = Formación Zuloaga. 


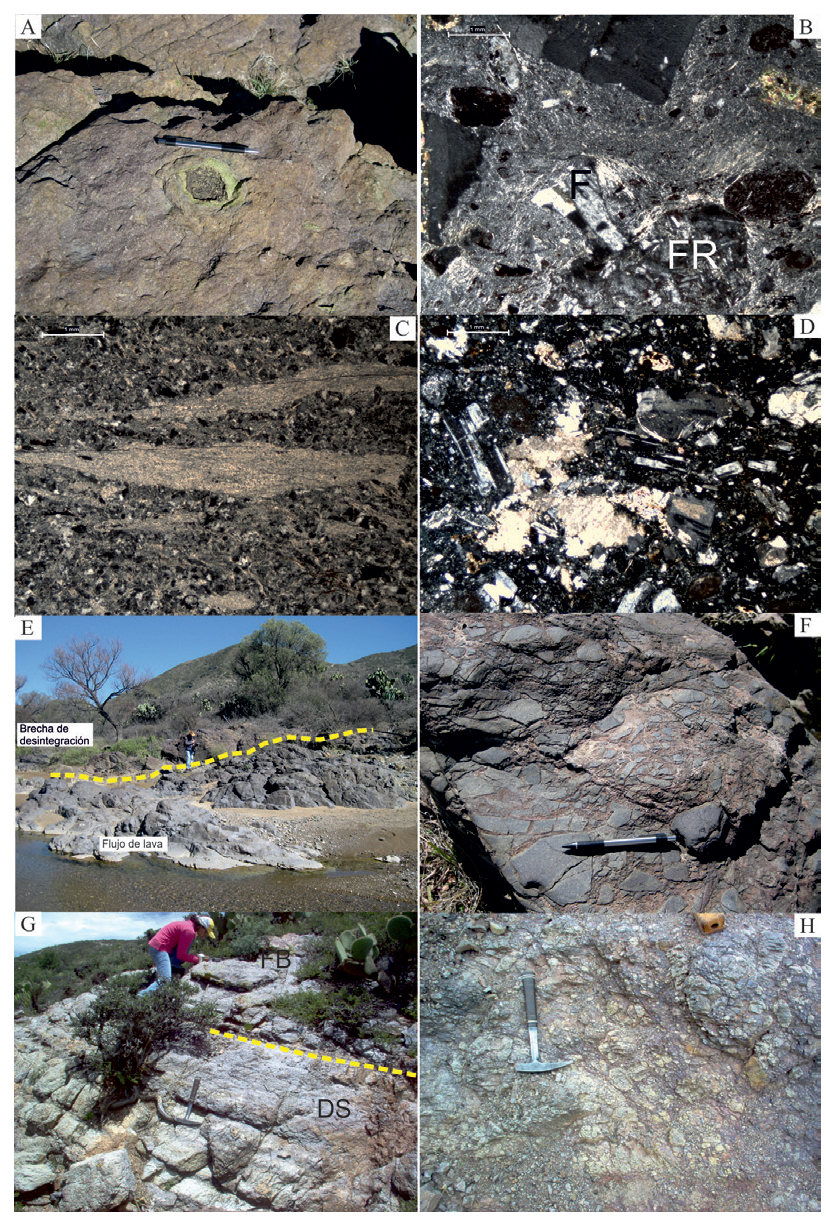

Figura 5. Aspectos generales de los diferentes tipos de depósitos que constituyen la secuencia volcánica del área de Charcas: (A) Flujo piroclástico brechoide con litofisas y fragmentos de roca volcánica; (B) Flujo piroclástico con fenocristales de feldespato ("F") y fragmentos de roca volcánica ("FR"), con una matriz fina de cenizas mostrando una textura fluidal; (C) Flujo piroclástico con formas alargadas de pómez y matriz cuarzo-feldespática; (D) Lava andesítica con fenocristales de plagioclasa englobados en una matriz microcristalina y carbonatos entre los intersticios; (E) Contacto entre un flujo de lava masivo y un flujo brechoide en forma de brecha de desintegración; (F) Detalle del flujo brechoide (brecha de desintegración), que incluye estructura de rompecabezas que generan los fragmentos de material volcánico, cementados por carbonatos; $(\mathrm{G})$ Aspecto general de un flujo piroclástico brechoide con abundantes esferulitas ("FB"), el cual hacia la base se comporta como una roca de grano fino muy silicificada y pseudoestratificada, con apariencia de depósito surge ("DS"); y $(\mathrm{H})$ Brecha volcánica con fragmentos subredondeados de roca volcánica, algunos de ellos fracturados, mostrando estructura de rompecabezas, con apariencia de debris flow.

Tras una nueva interrupción de varias decenas de metros a lo largo de la sección medida, se encuentra un pequeño afloramiento de roca volcánica andesítica brechada, similar a la descrita en el punto anterior, de color gris oscuro, sobreyacida por $\sim 50 \mathrm{~m}$ de espesor de un conglomerado polimíctico compuesto de fragmentos subredondeados de 2 $\mathrm{cm}$ a $10 \mathrm{~cm}$ de diámetro en una matriz arenosa. La mayoría de los componentes clásticos del conglomerado son rocas volcánicas como las ya descritas, además de fragmentos de arenisca, cuarcita y sílice amorfo. Este conglomerado pasa de manera transicional a una arenisca y, finalmente, a una limolita roja en una secuencia típica grano decreciente (finning upward).

Sobreyaciendo a la Formación Nazas, en un límite concordante y transicional, se presenta la Formación Zuloaga. Esta unidad está constituida por capas calcáreas, inicialmente arcillosas, de color gris claro a amarillo ocre, que cambian a bancos de caliza gris oscuro con bivalvos y gasterópodos.

\subsection{Sección Cerro La Medalla (B)}

Esta sección es la que presenta las condiciones de afloramiento más favorables para medir los espesores de las diferentes unidades volcánicas y epiclásticas presentes en el área. Se midió desde las coordenadas $23^{\circ} 05.106^{\prime}$ $\mathrm{N}, 101^{\circ} 10.652^{\prime} \mathrm{W}$, en la base de la sucesión volcánica, descansando sobre la Formación Zacatecas, hasta las coordenadas $23^{\circ} 5.012^{\prime} \mathrm{N}, 101^{\circ} 10.569^{\prime} \mathrm{W}$, en la base de la Formación Zuloaga. En la base de la sucesión volcánica existe un flujo piroclástico de $27 \mathrm{~m}$, brechoide, de color gris claro, con un ligero tono morado cuando se observa en superficie fresca. Contiene fenocristales de feldespato y líticos subangulosos de roca volcánica félsica, de hasta $10 \mathrm{~cm}$ de largo, así como abundantes esferulitas de $1 \mathrm{~cm}$ a $3 \mathrm{~cm}$ de diámetro. Las rocas se caracterizan por mostrar una matriz de cenizas y pseudoestratificación, como rasgo indicativo de un flujo subaéreo (Figura 5G).

Sobreyaciendo al flujo anterior se encuentran $22 \mathrm{~m}$ de una roca porfirítica de composición intermedia, con abundantes fenocristales de plagioclasa incluidos en una matriz microcristalina. Adicionalmente, ocurren esporádicos fragmentos subangulosos de roca volcánica ácida de color gris claro a verde olivo, de hasta $10 \mathrm{~cm}$ de largo, así como fragmentos de forma alargada o tabular de color negro, posiblemente cenizas, lutita o pizarra, y cuya abundancia se incrementa hacia la cima de esta unidad.

La sección continúa con un horizonte epiclástico rojizo de grano fino, con escasos fragmentos de plagioclasa, que hacia la cima cambia a una toba de grano fino que incluye pequeños fragmentos redondeados de color verde olivo, probablemente lapilli acrecional. Este horizonte, de cerca de $18 \mathrm{~m}$ de espesor, subyace a $36 \mathrm{~m}$ de un flujo piroclástico félsico brechoide de color gris claro a verdoso, con escasos fragmentos de cuarzo y fenocristales de feldespato en una matriz afanítica. Hacia la cima de este flujo se presentan 32 $m$ de una brecha volcánica con fragmentos subredondeados (diámetro $=2-15 \mathrm{~cm})$, de roca volcánica félsica similar a la de la base; además contiene escasos fenocristales de cuarzo. La brecha volcánica presenta matriz afanítica y se caracteriza porque algunos de los fragmentos presentan fracturas y se llegan a observar estructuras tipo rompecabezas, lo que indica un posible flujo de escombros (Figura 5H). Hacia la parte superior de este horizonte se incrementa la proporción de matriz arenosa y de cenizas hasta $\sim 70 \%$, quedando los clastos soportados por la matriz. 
Continúan $18 \mathrm{~m}$ de un depósito epiclástico de color rojo, con pequeños fragmentos de cuarzo lechoso, el cual subyace a $100 \mathrm{~m}$ de un conglomerado polimíctico soportado grano a grano, de color gris claro a morado, con fragmentos subredondeados de hasta $20 \mathrm{~cm}$ de diámetro, de roca volcánica, arenisca, limolita y cuarzo lechoso. Este depósito es considerado la base de la Formación La Joya, por lo que el espesor total para la Formación Nazas en esta sección es de $153 \mathrm{~m}$. Sobreyaciendo al conglomerado se presentan $63 \mathrm{~m}$ de una brecha muy compacta de color rojo púrpura a morado, con fragmentos subangulosos a redondeados de roca volcánica, lutita y cuarzo lechoso, soportados por una matriz arenosa. Ésta cambia hacia la cima a una brecha con abundantes fragmentos de forma alargada de color negro de posibles lutitas o pizarras. Dentro de esta brecha se encuentran intercaladas capas delgadas de arenisca de grano fino. Sobre esta brecha aparecen 18 $\mathrm{m}$ de arenisca de grano fino a limolita, de color rojo a rojo púrpura, que transicionalmente pasan a las calizas arcillosas de la Formación Zuloaga. El espesor total medido para la Formación La Joya de $181 \mathrm{~m}$.

\subsection{Sección cerro de Buenavista o camino a la Medalla (C)}

La sección medida al sur del cerro de Buenavista, a lo largo del camino a la localidad de La Medalla, inicia en las coordenadas $23^{\circ} 3.805^{\prime} \mathrm{N}, 101^{\circ} 11.010^{\prime} \mathrm{W}$ y culmina en las coordenadas $23^{\circ} 3.733^{\prime} \mathrm{N}, 101^{\circ} 10.966^{\prime} \mathrm{W}$. Aflora primeramente una secuencia de lutitas y limolitas o areniscas muy finas de color amarillento a verdoso, en alternancia rítmica de capas de $3 \mathrm{~cm}$ a $10 \mathrm{~cm}$ de espesor de la Formación Zacatecas, con estratificación ondulosa y marcas de corriente. En un límite discordante sobre la Formación Zacatecas, descansa una brecha polimíctica de color rojo a grisáceo de $27 \mathrm{~m}$ de espesor, la cual consiste, hacia su base, de fragmentos subangulosos a subredondeados, de $10 \mathrm{~cm}$ a $20 \mathrm{~cm}$ de diámetro, en una matriz arenosa. Los fragmentos son de rocas volcánicas andesíticas a riodacíticas y riolíticas. Contenido dentro de esta brecha, hacia su parte media inferior, se encuentra un banco de aproximadamente $4 \mathrm{~m}$ de espesor de un conglomerado polimíctico de color gris, silicificado y en parte cementado por carbonato de calcio.

Sobre la brecha polimíctica se encuentra un horizonte tobáceo de $\sim 1.0 \mathrm{~m}$ de espesor, de grano fino, color gris a morado. Ésta es la única roca claramente volcánica que aparece en esta localidad.

Continúan $10.5 \mathrm{~m}$ de arenisca fina a limolita color rojo violáceo, con intercalaciones esporádicas de delgados horizontes conglomeráticos. Sobre éstas se encuentra un conglomerado polimíctico de $3 \mathrm{~m}$ de espesor, con fragmentos subredondeados de riodacitas y andesitas, en una matriz arenosa. Los siguientes $34.5 \mathrm{~m}$ consisten de una brecha polimíctica, color rojizo a morado, con fragmentos subangulosos (diámetro $=3 \mathrm{~cm}$ a $5 \mathrm{~cm}$ ) en una matriz arenosa. Los fragmentos son de cuarzo lechoso, cuarcitas y algunas rocas volcánicas. Presenta una buena estratificación con alternancia mayor hacia su base de capas de $2 \mathrm{~m}$ a $5 \mathrm{~m}$ de espesor de arenisca de grano fino y limolita color rojo a violáceo.

Continúan $5 \mathrm{~m}$ de limolitas de color rojo violáceo, las cuales son sobreyacidas por un horizonte calcáreo de no más de $50 \mathrm{~cm}$ de espesor, el cual es a su vez sobreyacido por una brecha de $1 \mathrm{~m}$ de espesor, con fragmentos subangulosos de rocas volcánicas. Sobre esta brecha se presenta, de forma transicional, una secuencia constituida por una alternancia de calizas poco arcillosas intercaladas con calizas margosas en capas gruesas a bancos, de color amarillo crema y bancos de calizas de color gris sobreyacidas por capas gruesas a bancos de calizas micríticas de colores grises intermedios a gris oscuro, con abundantes bivalvos y diversos bioclastos. Continúan $18 \mathrm{~m}$ de alternancia de capas de color café ocre a grises de calizas arcillosas y margosas intercaladas con capas de $10 \mathrm{~cm}$ a $20 \mathrm{~cm}$ de espesor de calizas fosilíferas de color gris claro, con abundantes nerineas y bivalvos. En seguida se presentan $7 \mathrm{~m}$ de caliza microesparítica, de color gris claro, en capas gruesas a bancos de $50 \mathrm{~cm}$ a 60 $\mathrm{cm}$ de espesor.

Como puede observarse, sólo un horizonte tobáceo de $1.0 \mathrm{~m}$ de espesor puede considerarse estrictamente como una unidad volcánica, por lo que se puede considerar que el espesor de la sucesión volcánica considerada en esta sección como Formación Nazas es mucho menor que el que aparece en las otras secciones medidas, aun si a éste se agregan los $27 \mathrm{~m}$ de la brecha que la subyace (considerando un posible origen epiclástico para la misma).

\section{Metodología analítica}

El trabajo de campo incluyó, además de colectar las muestras para la descripción petrográfica de las diferentes unidades, la obtención de seis muestras de la sección arroyo San Antonio para los análisis geoquímicos, las cuales son representativas de los diferentes flujos que conforman la sucesión volcánica. Los elementos mayores de dos de estas muestras (VAR 07-16a y VAR 07-17b; Tabla 1) fueron realizados por fluorescencia de rayos $\mathrm{X}$ (XRF, $X$-ray fluorescence), en el Laboratorio de Geoquímica Isotópica (LUGIS) del Instituto de Geología, UNAM. En general, la precisión analítica reportada por el laboratorio fue $<1 \%$ para los elementos mayores, mientras que los límites de detección estuvieron en niveles de $0.01 \%$. La preparación de las muestras, las condiciones de medición del sistema secuencial SIEMENS SRS 3000 y el procedimiento de calibración fueron reportados por Lozano y Bernal (2005).

Por otra parte, la concentración de elementos traza de las muestras colectadas (Tabla 2), se determinó por espectrometría de masas acoplada a una fuente de plasma (ICP-MS, inductively coupled plasma mass spectrometry), en el Laboratorio de Geoquímica del Instituto de Geología de la Universidad Autónoma de San Luis Potosí. La 
Tabla 1. Composición química de elementos mayores (\% en peso) de rocas volcánicas de la Formación Nazas (Charcas, S.L.P.)

\begin{tabular}{ccc}
\hline Muestra & VAR 07-16a & VAR 07-17b \\
\hline Clasificación & Riodacita & Riodacita \\
\hline $\mathrm{SiO}_{2}$ & 80.79 & 47.78 \\
$\mathrm{TiO}_{2}$ & 0.28 & 0.57 \\
$\mathrm{Al}_{2} \mathrm{O}_{3}$ & 9.40 & 10.52 \\
$\mathrm{Fe}_{2} \mathrm{O}_{3}$ & 1.67 & 12.07 \\
$\mathrm{MnO}$ & 0.01 & 0.39 \\
$\mathrm{MgO}$ & 0.98 & 3.35 \\
$\mathrm{CaO}$ & 1.01 & 11.10 \\
$\mathrm{Na} \mathrm{O}_{2} \mathrm{O}$ & 0.24 & 2.84 \\
$\mathrm{~K}_{2} \mathrm{O}$ & 3.37 & 0.93 \\
$\mathrm{P}_{2} \mathrm{O}_{5}$ & 0.08 & 0.16 \\
$\mathrm{PPI}$ & 2.05 & 10.67 \\
Suma & 99.89 & 100.38 \\
\hline Clasificación de rocas con base en la propuesta de \\
Winchester y Floyd (1977). PPI = \% Pérdida por \\
ignición.
\end{tabular}

medición se realizó en un sistema cuadropolo Thermo X series II, siguiendo el método de preparación de muestras y las condiciones instrumentales sugeridas por Mori et al. (2007). La calibración del sistema se estableció utilizando ocho estándares del United States Geological Survey (basaltos BCR-2 y BHVO-1; diabasa W-2; andesitas AGV1 y AGV-2; sienita STM-1; cuarzolatita QLO-1; esquisto de micas SDC-1), que cubrieron un amplio espectro composicional de los elementos traza. La precisión de los análisis de elementos traza y tierras raras fue $<2 \%$. Los límites de detección se muestran en la Tabla 2.

Adicionalmente, se realizó la datación geocronológica U-Pb en circón de la muestra VAR 07-16, en el LaserChron Center, Universidad de Arizona, por medio de un sistema de espectrometría de masas acoplado a plasma e integrado a un equipo de ablación láser (LA-MC-ICP-MS, Laser Ablation Multicollector Inductively Coupled Plasma Mass Spectrometry), que cuenta con nueve colectores Faraday, un detector axial Daly y cuatro canales detectores de iones. La técnica de separación de circón, así como las condiciones

Tabla 2. Composición química de elementos traza (ppm) de rocas de la Formación Nazas (Charcas, S.L.P.)

\begin{tabular}{|c|c|c|c|c|c|c|c|}
\hline Muestra & VAR 07-15 & VAR 07-16a & VAR $07-15 b$ & VAR $07-16 \mathrm{c}$ & VAR 07-17a & VAR 07-17b & $\mathrm{LD}^{*}$ \\
\hline Clasificación & Riodacita & Riodacita & Riolita & Riodacita & Riodacita & Riodacita & \\
\hline $\mathrm{Li}$ & 44 & 32 & 26 & 39 & 87 & 77 & 0.008 \\
\hline $\mathrm{Sc}$ & 12.3 & 1.85 & 15.5 & 18.6 & 12.7 & 12.7 & 0.025 \\
\hline $\mathrm{Ti}$ & 2059 & 1326 & 2044 & 2678 & 5057 & 3178 & 0.365 \\
\hline V & 33 & 20 & 24 & 34 & 144 & 257 & 0.001 \\
\hline $\mathrm{Cr}$ & 74 & 9.26 & 11.5 & 8.6 & 24 & 17.0 & 0.029 \\
\hline $\mathrm{Co}$ & 5.3 & 1.84 & 2.67 & 2.77 & 24.52 & 29.23 & 0.003 \\
\hline $\mathrm{Ni}$ & 28 & 5.8 & 6.7 & 7.8 & 39 & 36 & 0.005 \\
\hline $\mathrm{Cu}$ & 3.79 & 2.95 & 3.12 & 2.08 & 1.64 & 4.72 & 0.021 \\
\hline $\mathrm{Zn}$ & 58 & 14.4 & 36 & 15.5 & 136 & 105 & 0.589 \\
\hline $\mathrm{Rb}$ & 123 & 105 & 71 & 152 & 43 & 27 & 0.001 \\
\hline $\mathrm{Sr}$ & 170 & 117 & 427 & 15.6 & 140 & 117 & 0.001 \\
\hline $\mathrm{Y}$ & 40 & 30 & 45 & 47 & 31 & 20 & 0.002 \\
\hline $\mathrm{Zr}$ & 160 & 122 & 234 & 148 & 117 & 83 & 0.002 \\
\hline $\mathrm{Nb}$ & 15.5 & 11.0 & 19.1 & 17.8 & 11.8 & 7.8 & 0.002 \\
\hline $\mathrm{Cs}$ & 23.7 & 8.20 & 14.94 & 14.91 & 7.03 & 3.29 & 0.001 \\
\hline $\mathrm{Ba}$ & 1570 & 2839 & 4092 & 846 & 307 & 160 & 0.019 \\
\hline $\mathrm{La}$ & 40 & 17 & 51 & 33 & 13.5 & 11.0 & 0.005 \\
\hline $\mathrm{Ce}$ & 106 & 45 & 118 & 76 & 35 & 22 & 0.004 \\
\hline $\operatorname{Pr}$ & 9.3 & 4.3 & 11.7 & 7.9 & 3.9 & 2.4 & 0.001 \\
\hline $\mathrm{Nd}$ & 36 & 15 & 41 & 36 & 20 & 15.0 & 0.004 \\
\hline $\mathrm{Sm}$ & 8.1 & 5.2 & 11.6 & 7.2 & 4.1 & 2.7 & 0.0006 \\
\hline $\mathrm{Eu}$ & 2.0 & 1.4 & 3.1 & 1.7 & 0.9 & 0.7 & 0.0001 \\
\hline Gd & 6.8 & 4.2 & 9.1 & 7.6 & 4.4 & 3.1 & 0.0005 \\
\hline $\mathrm{Tb}$ & 1.1 & 0.7 & 1.5 & 1.2 & 0.7 & 0.5 & 0.0001 \\
\hline Dy & 6.2 & 4.1 & 7.8 & 6.3 & 3.9 & 2.8 & 0.0004 \\
\hline Ho & 1.4 & 1.0 & 1.7 & 1.3 & 0.8 & 0.6 & 0.0001 \\
\hline $\mathrm{Er}$ & 3.3 & 2.4 & 4.1 & 3.6 & 2.6 & 2.2 & 0.0002 \\
\hline $\mathrm{Tm}$ & 0.5 & 0.39 & 0.7 & 0.6 & 0.36 & 0.28 & 0.0001 \\
\hline $\mathrm{Yb}$ & 3.4 & 2.7 & 4.0 & 3.4 & 2.2 & 1.8 & 0.0002 \\
\hline $\mathrm{Lu}$ & 0.5 & 0.39 & 0.6 & 0.5 & 0.35 & 0.31 & 0.0001 \\
\hline $\mathrm{Hf}$ & 4.3 & 3.1 & 6.0 & 3.7 & 3.0 & 1.8 & 0.003 \\
\hline $\mathrm{Ta}$ & 1.1 & 0.8 & 1.3 & 1.1 & 0.8 & 0.5 & 0.002 \\
\hline $\mathrm{Tl}$ & 0.6 & 0.5 & 0.40 & 0.8 & 0.27 & 0.17 & 0.001 \\
\hline $\mathrm{Pb}$ & 8.4 & 5.1 & 18 & 10 & 3.79 & 6.6 & 0.025 \\
\hline $\mathrm{Th}$ & 15.7 & 11.5 & 20.7 & 9.6 & 5.3 & 0.8 & 0.001 \\
\hline $\mathrm{U}$ & 1.80 & 1.70 & 2.46 & 2.20 & 1.82 & 1.65 & 0.005 \\
\hline
\end{tabular}


analíticas del sistema son descritas a detalle en Gehrels et al. (2008). La información isotópica y geocronológica U-Pb generada se reportan en la Tabla 3.

\section{Estudios geoquímicos de la sucesión volcánica}

La sucesión volcánica de la Formación Nazas presenta un intervalo amplio de composición en algunos elementos mayores (Tabla 1; por ejemplo: $\% \mathrm{SiO}_{2}=47.8-80.8 \%$; $\% \mathrm{Fe}_{2} \mathrm{O}_{3}{ }^{\mathrm{t}}=1.7-12.1 \% ; \% \mathrm{CaO}=1.0-11.1 \%$ ). Las rocas se caracterizan además por mostrar diversos grados de alteración, que se reflejan en valores de pérdida por ignición de $2 \%$ a $10 \%$, por lo que no es recomendable utilizar los esquemas tradicionales de clasificación de rocas volcánicas frescas (Rollinson, 1993). Los elementos traza relativamente inmóviles han sido utilizados para la clasificación de rocas volcánicas alteradas (Winchester y Floyd, 1977; Floyd y Winchester, 1978), aunque la eficiencia de estos esquemas ha sido cuestionada recientemente (Verma et al., 2010). En la Figura 6 se presenta la clasificación de las rocas volcánicas de la Formación Nazas basada en las relaciones $\mathrm{Zr} / \mathrm{Ti}$ (un indicador de diferenciación química) y Nb/Y (un indicador de alcalinidad), donde las muestras, con excepción de la riolita VAR 07-15b, se ubican en el campo de riodacita.

Las rocas volcánicas de la Formación Nazas se caracterizan por mostrar patrones de elementos de las tierras raras, normalizados a condrita (Figura 7):(a) enriquecidos en elementos ligeros $\left([\mathrm{La} / \mathrm{Yb}]_{\mathrm{N}}=4.1-7.9\right)$; (b) una pequeña anomalía negativa de $\mathrm{Eu}$; (c) un patrón plano de elementos pesados; y (d) un enriquecimiento general del grupo de elementos con la evolución de riodacita $(\mathrm{Zr} /$

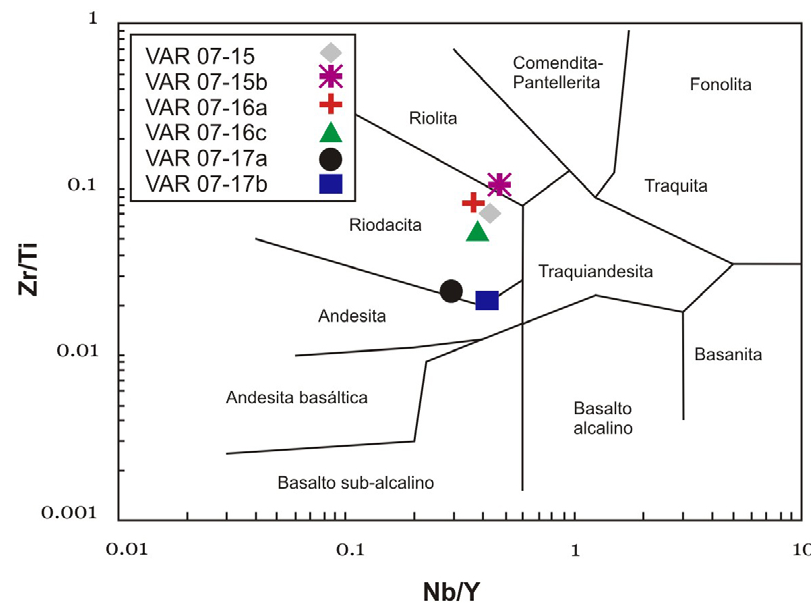

Figura 6. Diagrama de clasificación $\mathrm{Zr} / \mathrm{Ti}-\mathrm{Nb} / \mathrm{Y}$ para rocas volcánicas alteradas de Winchester y Floyd (1977) aplicado a la secuencia volcánica Nazas.

Tabla 3. Datos analíticos U-Pb por la técnica MC-LA-ICPMS en zircones de roca riodacítica de la zona San Antonio de Las Huertas, Charcas, S.L.P.

\begin{tabular}{|c|c|c|c|c|c|c|c|c|c|c|c|c|c|c|c|c|c|c|}
\hline \multirow[b]{2}{*}{$\begin{array}{l}\begin{array}{l}\text { Zircón } \\
\text { (spot) }\end{array} \\
\end{array}$} & \multirow[b]{2}{*}{$\begin{array}{c}\mathrm{U} \\
(\mathrm{ppm})\end{array}$} & \multirow[b]{2}{*}{ U/Th } & \multirow[b]{2}{*}{$\begin{array}{l}206 \mathrm{~Pb} / \\
204 \mathrm{~Pb}\end{array}$} & \multicolumn{7}{|c|}{ Relaciones Isotópicas } & \multicolumn{8}{|c|}{ Edades Aparentes (Ma) } \\
\hline & & & & $\begin{array}{l}206 \mathrm{~Pb}^{* /} \\
207 \mathbf{P b}^{*}\end{array}$ & $\begin{array}{c} \pm \\
(\%)\end{array}$ & $\begin{array}{c}207 \mathbf{P b}^{* / /} \\
235 \mathbf{U}^{*}\end{array}$ & $\begin{array}{c} \pm \\
(\%)\end{array}$ & $\begin{array}{c}206 P^{*} * / \\
238 U^{*}\end{array}$ & $\begin{array}{c} \pm \\
(\%)\end{array}$ & errorcorr. & $\begin{array}{c}206 \mathrm{~Pb}^{* /} \\
238 \mathrm{U}^{*}\end{array}$ & $\begin{array}{c} \pm \\
(\mathbf{M a})\end{array}$ & $\begin{array}{c}207 \mathrm{~Pb}^{* / 1} \\
235 \mathrm{U}^{*}\end{array}$ & $\begin{array}{c} \pm \\
\text { (Ma) }\end{array}$ & $\begin{array}{l}206 \mathrm{~Pb}^{* /} \\
207 \mathrm{~Pb}^{*}\end{array}$ & $\begin{array}{c} \pm \\
\text { (Ma) }\end{array}$ & $\begin{array}{c}\text { EDAD } \\
\text { (Ma) }\end{array}$ & $\begin{array}{c} \pm \\
(\mathrm{Ma}) \\
\end{array}$ \\
\hline \multicolumn{19}{|c|}{ VAR 07-16 Riodacita San Antonio de las Huertas $\left(23^{\circ} 5.727^{\prime} \mathrm{N}-101^{\circ} 10.795^{\prime} \mathrm{W}\right)$} \\
\hline 6 & 122 & 2.5 & 4980 & 21.759 & 8.4 & 0.1716 & 8.9 & 0.02710 & 2.7 & 0.310 & 172.3 & 4.7 & 160.8 & 13 & -4.5 & 204 & 172.3 & 4.7 \\
\hline 3 & 157 & 1.9 & 3051 & 21.461 & 13.0 & 0.1743 & 13.4 & 0.02710 & 3.0 & 0.220 & 172.6 & 5.1 & 163.1 & 20 & 28.5 & 314 & 172.6 & 5.1 \\
\hline 24 & 101 & 2.4 & 1746 & 16.986 & 15.3 & 0.2232 & 15.6 & 0.02750 & 2.8 & 0.180 & 174.9 & 4.8 & 204.6 & 29 & 562.3 & 335 & 174.9 & 4.8 \\
\hline 11 & 129 & 2.5 & 4647 & 20.566 & 10.8 & 0.1857 & 11.0 & 0.02770 & 1.8 & 0.160 & 176.2 & 3.1 & 173.0 & 17 & 129.8 & 255 & 176.2 & 3.1 \\
\hline 28 & 129 & 2.3 & 4449 & 19.288 & 12.8 & 0.1982 & 12.8 & 0.02770 & 1.0 & 0.080 & 176.3 & 1.7 & 183.6 & 22 & 278.6 & 293 & 176.3 & 1.7 \\
\hline 16 & 178 & 2.9 & 8268 & 21.917 & 11.3 & 0.1745 & 11.4 & 0.02770 & 1.3 & 0.120 & 176.4 & 2.3 & 163.3 & 17 & -22.1 & 275 & 176.4 & 2.3 \\
\hline 4 & 122 & 2.5 & 3138 & 21.487 & 11.3 & 0.1783 & 11.4 & 0.02780 & 1.6 & 0.140 & 176.6 & 2.7 & 166.6 & 18 & 25.6 & 271 & 176.6 & 2.7 \\
\hline 9 & 124 & 3.0 & 7413 & 21.763 & 6.8 & 0.1761 & 6.9 & 0.02780 & 1.1 & 0.150 & 176.8 & 1.8 & 164.7 & 11 & -5.1 & 165 & 176.8 & 1.8 \\
\hline 25 & 154 & 2.2 & 3807 & 18.133 & 12.7 & 0.2115 & 12.7 & 0.02780 & 1.0 & 0.080 & 176.8 & 1.7 & 194.8 & 23 & 418.2 & 284 & 176.8 & 1.7 \\
\hline 1 & 109 & 2.3 & 3690 & 21.482 & 17.9 & 0.1787 & 18.2 & 0.02780 & 3.4 & 0.180 & 177.0 & 5.9 & 166.9 & 28 & 26.2 & 432 & 177.0 & 5.9 \\
\hline 14 & 310 & 2.4 & 8037 & 20.227 & 4.0 & 0.1898 & 4.1 & 0.02780 & 1.0 & 0.240 & 177.0 & 1.7 & 176.4 & 7 & 168.7 & 94 & 177.0 & 1.7 \\
\hline 8 & 96 & 1.9 & 561 & 16.699 & 14.3 & 0.2309 & 14.4 & 0.02800 & 1.3 & 0.090 & 177.8 & 2.3 & 211.0 & 27 & 599.4 & 312 & 177.8 & 2.3 \\
\hline 10 & 104 & 2.6 & 24159 & 20.746 & 15.8 & 0.1877 & 16.0 & 0.02820 & 2.4 & 0.150 & 179.5 & 4.2 & 174.6 & 26 & 109.2 & 375 & 179.5 & 4.2 \\
\hline 20 & 117 & 2.4 & 4473 & 19.474 & 14.4 & 0.2016 & 14.7 & 0.02850 & 2.7 & 0.180 & 181.0 & 4.8 & 186.5 & 25 & 256.6 & 333 & 181.0 & 4.8 \\
\hline 15 & 191 & 3.0 & 6357 & 22.310 & 10.0 & 0.1766 & 10.1 & 0.02860 & 1.0 & 0.100 & 181.6 & 1.8 & 165.1 & 15 & -65.3 & 245 & 181.6 & 1.8 \\
\hline 13 & 162 & 1.9 & 10440 & 19.126 & 8.4 & 0.2064 & 8.4 & 0.02860 & 1.0 & 0.120 & 181.9 & 1.8 & 190.5 & 15 & 297.9 & 191 & 181.9 & 1.8 \\
\hline 5 & 214 & 1.7 & 6243 & 20.666 & 3.8 & 0.1913 & 4.0 & 0.02870 & 1.4 & 0.340 & 182.2 & 2.5 & 177.7 & 7 & 118.3 & 89 & 182.2 & 2.5 \\
\hline 19 & 136 & 2.3 & 6660 & 20.716 & 15.1 & 0.1913 & 15.2 & 0.02870 & 1.1 & 0.070 & 182.7 & 1.9 & 177.7 & 25 & 112.6 & 359 & 182.7 & 1.9 \\
\hline 23 & 129 & 1.7 & 2457 & 18.196 & 12.5 & 0.2184 & 12.5 & 0.02880 & 1.0 & 0.080 & 183.2 & 1.8 & 200.6 & 23 & 410.4 & 280 & 183.2 & 1.8 \\
\hline 21 & 103 & 2.7 & 3567 & 20.186 & 17.0 & 0.1974 & 17.1 & 0.02890 & 1.5 & 0.090 & 183.6 & 2.7 & 182.9 & 29 & 173.4 & 399 & 183.6 & 2.7 \\
\hline 29 & 150 & 2.3 & 4047 & 20.815 & 14.7 & 0.1928 & 14.7 & 0.02910 & 1.0 & 0.070 & 185.0 & 1.9 & 179.0 & 24 & 101.3 & 349 & 185.0 & 1.9 \\
\hline 2 & 120 & 1.3 & 1764 & 20.355 & 10.0 & 0.2013 & 10.0 & 0.02970 & 1.3 & 0.130 & 188.8 & 2.4 & 186.2 & 17 & 154 & 234 & 188.8 & 2.4 \\
\hline 22 & 104 & 1.6 & 1692 & 18.637 & 12.2 & 0.2213 & 12.4 & 0.02990 & 2.0 & 0.160 & 190.0 & 3.8 & 203.0 & 23 & 356.7 & 277 & 190.0 & 3.8 \\
\hline 27 & 107 & 2.2 & 5127 & 16.625 & 10.0 & 0.2539 & 10.0 & 0.03060 & 1.0 & 0.100 & 194.4 & 1.9 & 229.7 & 21 & 609 & 216 & 194.4 & 1.9 \\
\hline 26 & 53 & 1.4 & 3900 & 14.230 & 11.2 & 0.3083 & 11.8 & 0.03180 & 3.8 & 0.320 & 201.9 & 7.6 & 272.8 & 28 & 936.3 & 230 & 201.9 & 7.6 \\
\hline 18 & 164 & 3.2 & 8166 & 17.981 & 2.9 & 0.3989 & 3.6 & 0.05200 & 2.1 & 0.580 & 326.9 & 6.7 & 340.9 & 10 & 437 & 65 & 326.9 & 6.7 \\
\hline 30 & 150 & 1.6 & 10056 & 18.126 & 3.7 & 0.4352 & 4.8 & 0.05720 & 3.1 & 0.640 & 358.7 & 10.7 & 366.9 & 15 & 419.1 & 83 & 358.7 & 10.7 \\
\hline 12 & 94 & 5.1 & 10935 & 14.842 & 4.0 & 0.8032 & 7.2 & 0.08650 & 6.0 & 0.830 & 534.5 & 30.9 & 598.6 & 33 & 849.5 & 84 & 534.5 & 30.9 \\
\hline 7 & 295 & 6.1 & 54999 & 13.236 & 1.7 & 1.9101 & 2.0 & 0.18340 & 1.2 & 0.580 & 1085.3 & 11.8 & 1084.6 & 14 & 1083.2 & 34 & 1083.2 & 33.5 \\
\hline
\end{tabular}




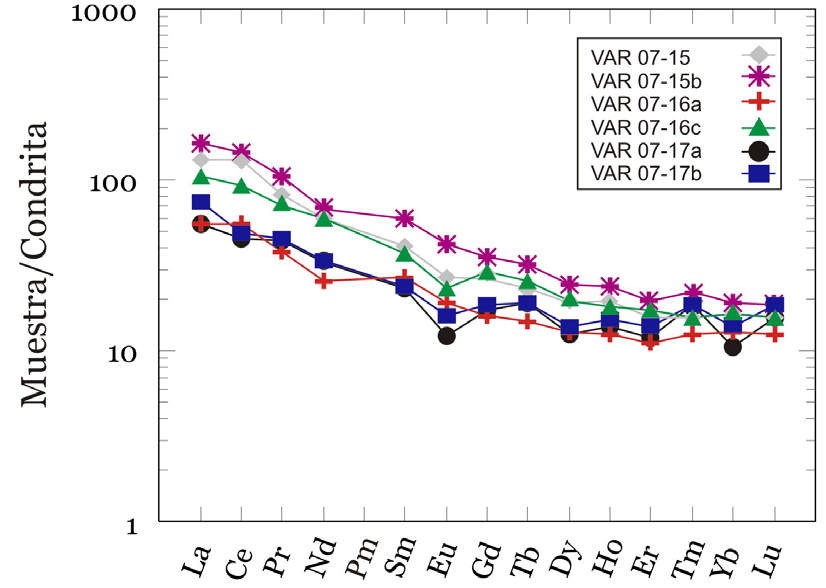

Figura 7. Patrones de lantánidos normalizados a condrita de rocas volcánicas representativas de la secuencia volcánica Nazas de la sección arroyo San Antonio (Charcas, S.L.P.). Datos de normalización de condrita en ppm (Rollinson, 1993): $\mathrm{La}=0.310, \mathrm{Ce}=0.808, \mathrm{Pr}=0.112, \mathrm{Nd}=0.600$, $\mathrm{Sm}=0.195, \mathrm{Eu}=0.074, \mathrm{Gd}=0.259, \mathrm{~Tb}=0.047, \mathrm{Dy}=0.322, \mathrm{Ho}=0.072$, $\mathrm{Er}=0.210, \mathrm{Tm}=0.032, \mathrm{Yb}=0.209, \mathrm{Lu}=0.032$.

$\mathrm{Ti}=0.02)$ a riolita $(\mathrm{Zr} / \mathrm{Ti}=0.11)$. Estas características indican la derivación de una fuente magmática enriquecida en elementos incompatibles, una evolución magmática dominada por la cristalización fraccionada con una separación limitada de plagioclasa (Wilson, 1989).

Por otra parte, la composición de elementos traza de la secuencia volcánica de la Formación Nazas se ha utilizado para construir diagramas multielementos, normalizados a manto primitivo (Figura 8A). Estos gráficos se caracterizan, en general, por: (a) un enriquecimiento en elementos altamente incompatibles (Cs $\sim 1-3 \times 10^{3^{*}}$ manto primitivo), que disminuye conforme se incrementa la compatibilidad y que concluye con un patrón plano entre $\mathrm{Gd} \mathrm{y} \mathrm{Lu;} \mathrm{(b)} \mathrm{un}$ patrón en zigzag, que incluye anomalías negativas de Sr y de elementos de alto potencial iónico (Nb, Ta, Zr, Hf y Ti); y (c) una anomalía positiva de $\mathrm{Pb}$. Con la excepción de algunas variaciones en $\mathrm{Rb}, \mathrm{Ba}$ y $\mathrm{Th}$, las rocas analizadas muestran patrones comparables, lo que podría ser indicativo de que derivaron de una fuente magmática común. Este tipo de patrones se ha asociado a magmas generados en ambientes de arco (Wilson, 1989). Los enriquecimientos en Cs, Rb, $\mathrm{Ba}$ y $\mathrm{Pb}$ podrían ser atribuidos al transporte preferencial de estos elementos móviles por los fluidos acuosos de alta temperatura generados durante la deshidratación de la placa en subducción (Wilson, 1989; White, 2005).

Por otro lado, las rocas volcánicas de la Formación Nazas que afloran en el valle de Huizachal, Tamaulipas, y en Aramberri, Nuevo León, (García-Obregón, 2007) presentan patrones similares con anomalías negativas de $\mathrm{Nb}$ y Ta, así como en $\mathrm{Sr}$ y Ti (Figura 8B). Sin embargo, las rocas volcánicas de la Formación La Silla, Sierra de Chiapas, asociadas al Arco Nazas (Godínez-Urban et al., 2011), se caracterizan por patrones comparables a los de la sucesión volcánica bajo estudio, aunque las anomalías negativas de

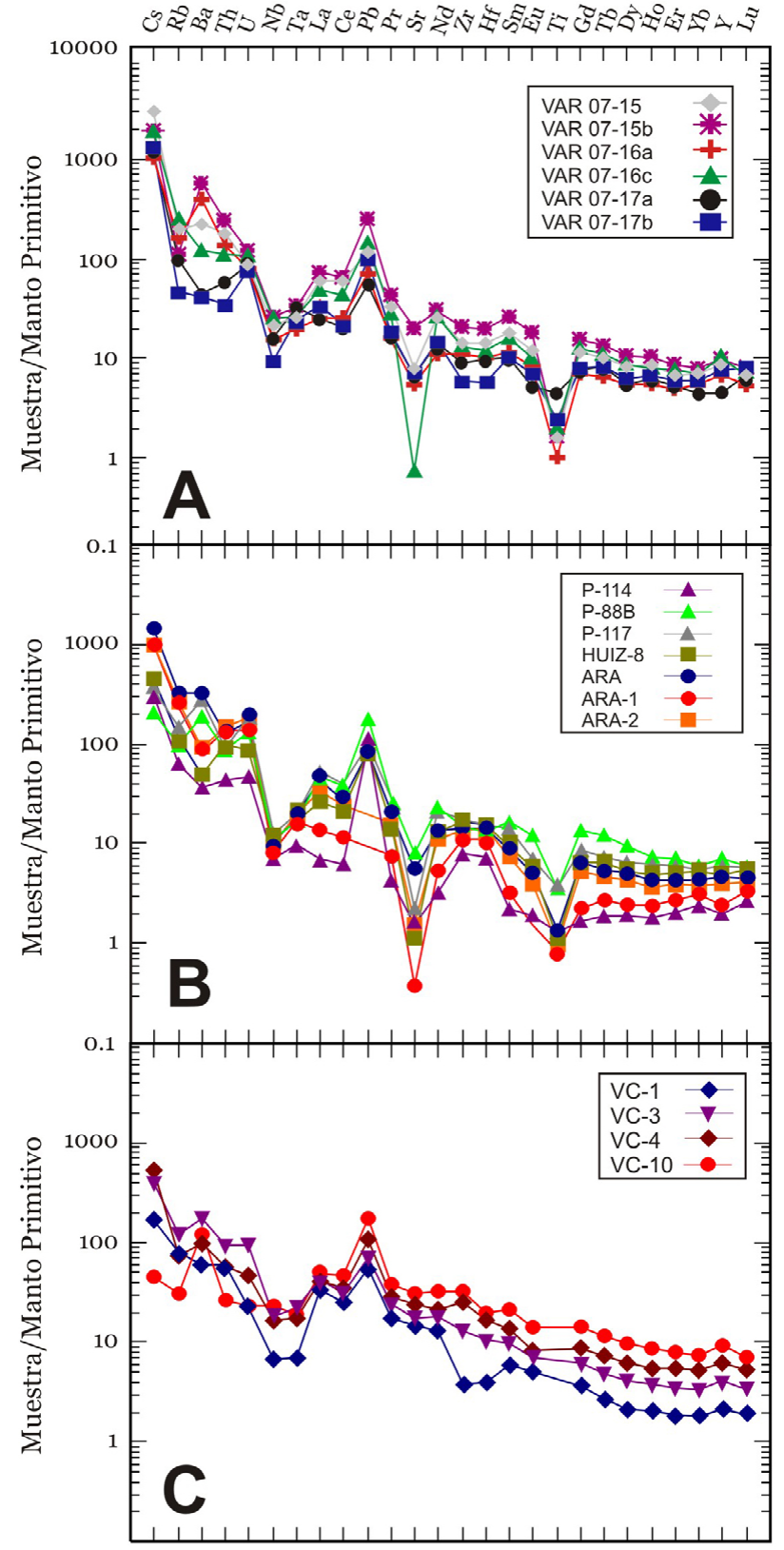

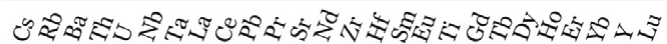

Figura 8. Diagramas multielemento normalizados amanto primitivo, de acuerdo al arreglo y valores de normalización (en ppm) propuestos por Sun y McDonough (1989): $\mathrm{Cs}=0.032, \mathrm{Rb}=0.635, \mathrm{Ba}=6.989, \mathrm{Th}=0.085, \mathrm{U}$ $=0.021, \mathrm{Nb}=0.713, \mathrm{Ta}=0.041, \mathrm{La}=0.687, \mathrm{Ce}=1.775, \mathrm{~Pb}=0.185, \mathrm{Pr}$ $=0.276, \mathrm{Sr}=21.1, \mathrm{Nd}=1.354, \mathrm{Zr}=11.2, \mathrm{Hf}=0.309, \mathrm{Sm}=0.444, \mathrm{Eu}=$ $0.168, \mathrm{Ti}=1300, \mathrm{Gd}=0.596, \mathrm{~Tb}=0.108, \mathrm{Dy}=0.737, \mathrm{Ho}=0.164, \mathrm{Er}=$ $0.480, \mathrm{Yb}=0.493, \mathrm{Y}=4.55, \mathrm{Lu}=0.074$. (A) Secuencia volcánica jurásica del arroyo San Antonio (Charcas, S.L.P.); (B) Rocas volcánicas del valle de Huizachal, Tamaulipas, y Aramberri, Nuevo León (García-Obregón, 2007); y (C) Rocas volcánicas de la Formación La Silla, sierra de Chiapas (Godínez-Urban et al., 2011).

Sr y Ti son ausentes (Figura 8C).

Para profundizar sobre la génesis de la secuencia volcánica de la Formación Nazas se utilizaron diagramas de discriminación tectonomagmática tradicionales (Figura9). 
En primera instancia se aplicó el diagrama Th- $\mathrm{Hf} / 3-\mathrm{Ta}$ (Figura 9a), aunque éste se ha utilizado para distinguir entre magmas basálticos generados en márgenes destructivos y aquellos asociados a ambientes de cresta oceánica o intraplaca (Wood, 1980). Con excepción de la riodacita VAR 07-17b, todas las rocas se ubican en el campo de basaltos de arco volcánico calcoalcalino. Para superar la deficiencia en cuanto a tipo de roca, se aplicó el diagrama $\mathrm{Rb}-(\mathrm{Y}+$ $\mathrm{Nb}$ ) (Figura 9b) propuesto por Pearce et al. (1984) para la discriminación de rocas graníticas. Las rocas volcánicas con una relación $\mathrm{Zr} / \mathrm{Ti}=0.08-0.11$ se ubican en el campo de los granitos intraplaca, mientras que aquellas con $\mathrm{Zr} / \mathrm{Ti}=0.02$ 0.06 lo hacen en el campo de los granitos de arco volcánico. Recientemente, Verma et al. (2012) criticaron la efectividad de discriminación de los diagramas de Pearce et al. (1984),
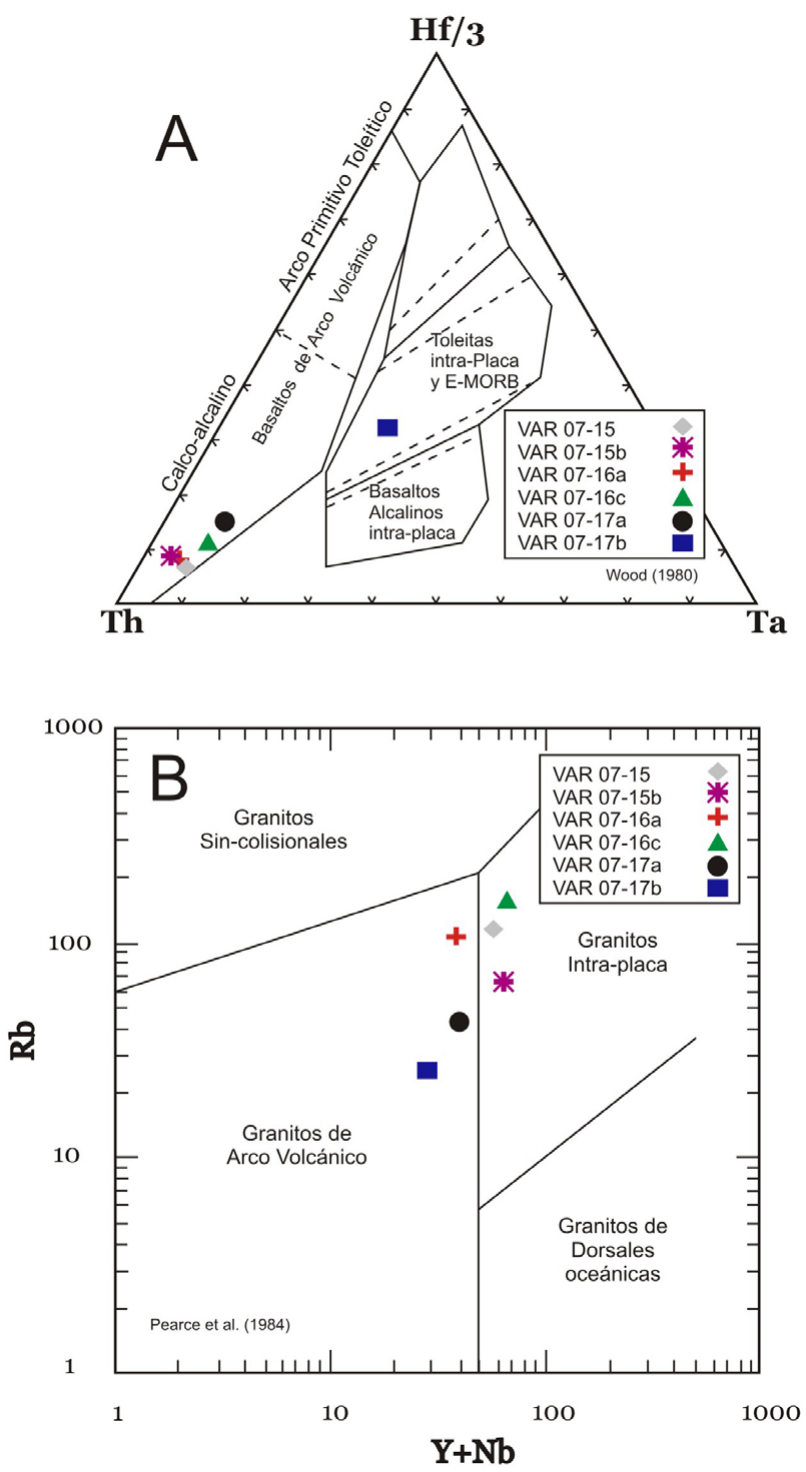

Figura 9. Discriminación tectonomagmática de las rocas volcánicas de la Formación Nazas: (A) Diagrama Th-Hf/3-Ta para magmas basálticos (Wood, 1980);(B) Diagrama $\mathrm{Rb}-(\mathrm{Y}+\mathrm{Nb}$ ) para rocas graníticas (Pearce et al., 1984). desarrollando nuevos diagramas multidimensionales basados en funciones estadísticas discriminantes de elementos mayores. La aplicación de este esquema a las rocas volcánicas de la Formación Nazas (Figuras 10A, 10B y 10C) indica que es probable la asociación de una parte de las rocas a un ambiente de arco continental, mientras que la
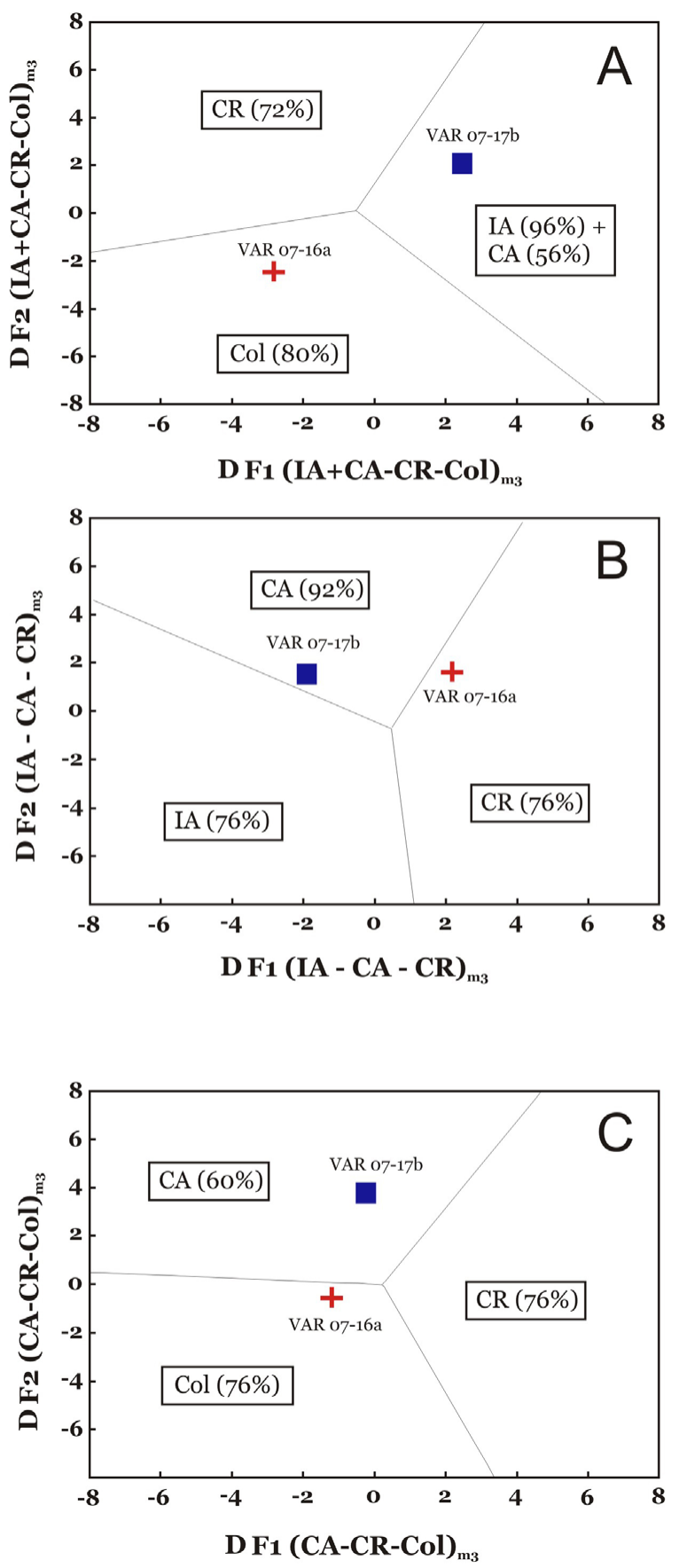

Figura 10. Discriminación tectonomagmática de las rocas volcánicas de la Formación Nazas basada en diagramas multidimensionales de funciones discriminantes DF1-DF2 para rocas ácidas de arco insular (IA), arco continental (CA), rift continental (CR) y ambiente de colisión (Col) (Verma et al.,2012): (A) IA + CA-CR-Col; (B) IA-CA-CR; (C) CA-CR-Col. 
otra podría haberse generado en un ambiente de colisión.

\section{Geocronología U-Pb en circones}

La metodología de separación de circones y su análisis isotópico $\mathrm{U}-\mathrm{Pb}$ fue aplicada a la riodacita VAR 07-16 (Figuras 3 y 4), que forma parte de un flujo piroclástico de composición riodacítica de la localidad San Antonio de las Huertas (Figura 2; 23⒌727' N; 101⒑795' W). Se realizaron un total de 29 análisis isotópicos $\mathrm{U}-\mathrm{Pb}$ (Tabla 3 ), de los cuales cuatro se han considerado como circones heredados de edades paleozoica y mesoproterozoica (Figura 11A). Una ampliación del diagrama de Wetherill a los circones más jóvenes (Figura11B), muestra una agrupación coherente de 19 análisis (elipses en color negro) de los que se obtuvo una edad ${ }^{206} \mathrm{~Pb} /{ }^{238} \mathrm{U}$ media ponderada de $179 \pm 1$ Ma (MSWD = 1.7, 2-sigma; Figura 11C). Los seis análisis restantes (elipses en color gris) probablemente representan algún grado de herencia, por lo que fueron descartados para el cálculo de la media ponderada. De acuerdo a lo anterior, esta edad jurásica se podría interpretar como la edad de cristalización de la unidad volcánica de composición riodacítica incluida en la sección San Antonio de Las Huertas (Charcas, S.L.P.).

\section{Discusión}

Las relaciones estratigráficas observadas durante el presente estudio corroboran la correlación de la sucesión de rocas volcánicas expuesta en Charcas, San Luis Potosí, con aquéllas pertenecientes al vulcanismo de arco continental del Jurásico Inferior del Noreste de México (Figura 12), ya que: 1) sobreyacen en discordancia angular a rocas siliciclásticas del Triásico Superior (Formación Zacatecas) con edades máximas de depósito de 230 - 225 Ma por $\mathrm{U}-\mathrm{Pb}$ en circones para Real de Catorce y de $254 \mathrm{Ma}$ para el área de Charcas (Barboza-Gudiño et al., 2010); y 2) son sobreyacidas discordantemente por capas rojas del Jurásico Medio (Bathoniano-Calloviano) de la Formación La Joya. Lo anterior sugiere que el vulcanismo ocurrió, al menos para la parte central de México, a principios del Jurásico.

Los productos volcánicos de la unidad estudiada se observan, al igual que en otras áreas a nivel regional, distribuidos de manera discontinua, ya que en áreas relativamente cercanas las rocas volcánicas pueden o no estar presentes, o bien presentar grandes y repentinas variaciones en su espesor, lo que podría indicar un depósito sobre una topografía muy irregular. Además, de que por su naturaleza los productos volcánicos se concentran en diversas acumulaciones en torno a las áreas fuente o por mecanismos de flujo que determinan una distribución irregular. El espesor de la secuencia volcánica en las secciones medidas, distantes aproximadamente entre $1.5 \mathrm{y}$ $2 \mathrm{~km}$, fue de únicamente $28 \mathrm{~m}$ de un depósito epiclástico, hasta $153 \mathrm{~m}$ medidos en la sucesión volcánica expuesta en la sección cerro La Medalla. Esta sucesión volcánica subyace en discordancia angular a los depósitos continentales del Calloviano-Oxfordiano de la Formación La Joya, la cual también se encuentra distribuida de forma irregular, con un espesor mínimo dentro del área de estudio de $43 \mathrm{~m}$ y un máximo de $181 \mathrm{~m}$. Se caracteriza por tener fragmentos de origen volcánico principalmente, aunque llega a contener también clastos de rocas más antiguas, especialmente de la sucesión siliciclástica marina del Triásico Superior (Formación Zacatecas).

De acuerdo a la composición de sus productos, la sucesión volcánica ha sido interpretada como parte del arco volcánico continental de edad Jurásico Temprano a Medio en la margen paleopacífica de México. Las relaciones de elementos inmóviles indican una composición riodacítica
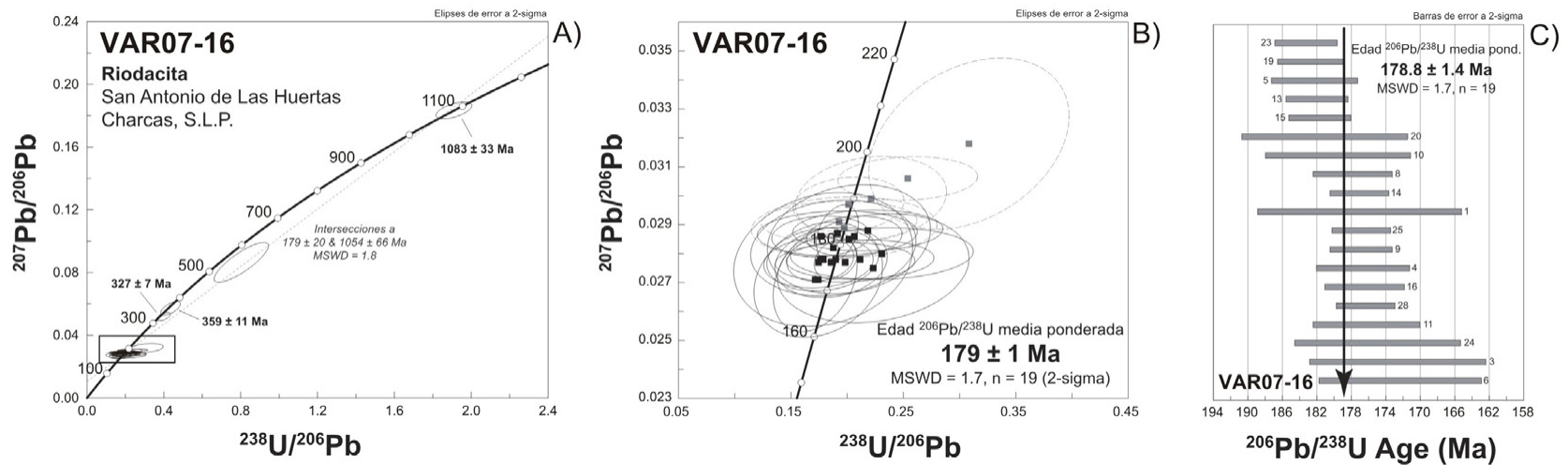

Figura 11. Geocronología U-Pb en circón, por medio del método LA-MC-ICP-MS, para la riodacita VAR 07-16, sección San Antonio de Las Huertas (Charcas, S.L.P.) (A) Diagrama de concordia tipo Wetherill, que incluye circones heredados de edad paleozoica y mesoproterozoica; (B) Detalle del gráfico (A) para los datos más jóvenes, en donde se muestra una edad de cristalización de $179 \pm 1 \mathrm{Ma}(\mathrm{n}=19 ; \mathrm{MSWD}=1.7)$. Los análisis concordantes, utilizados para calcular la edad media ponderada, están representados por las elipses con línea continua, mientras que las elipses con línea discontinua reportan los análisis discordantes, que posiblemente representan algún grado de herencia. (C) Gráfico de edad ${ }^{206} \mathrm{~Pb} /{ }^{238} \mathrm{U}$ media ponderada, con su error asociado, para los cristales estudiados en la muestra. 


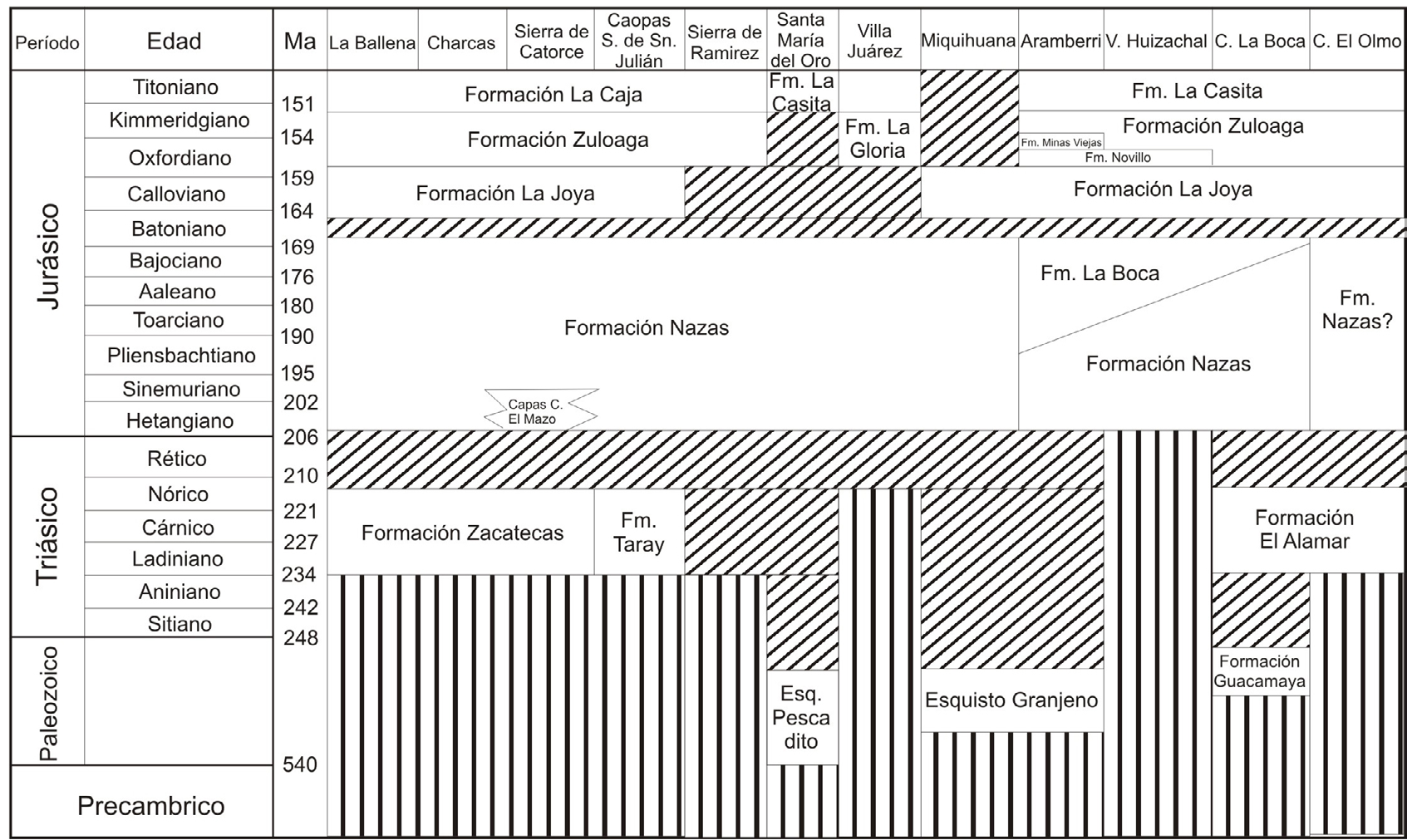

Figura 12. Correlación estratigráfica de las secuencias volcánicas jurásicas (Formación Nazas) en el Noreste de Mexico. Modificada de Barboza-Gudiño et al. (2008).

y riolítica. Los diagramas multielemento muestran patrones en zigzag, con un desacoplamiento entre elementos litófilos de ión grande (LILE, large ion lithophile elements) y aquellos de alta densidad de carga (HFSE, high field strength elements), que son característicos de magmas relacionados a subducción. Los diagramas de discriminación indican una asociación a un ambiente de arco continental, aunque la afinidad tectónica para algunas muestras resultó incierta. Sin embargo, de forma general, se podría relacionar la génesis de este vulcanismo con la subducción de la placa Mezcalera bajo la margen paleopacífica de México durante el Jurásico Temprano y Medio (Dickinson y Lawton, 2001). Magmatismo de arco continental del Jurásico Inferior a Medio, se ha documentado en el área de Aramberri y valle del Huizachal (García-Obregón, 2007), así como en la Sierra de Chiapas, Chiapas (Godínez-Urban et al., 2011). En todos los casos, las sucesiones volcánicas presentan patrones multielementos típicos de magmas de arco continental. Sin embargo, las rocas de la Formación La Silla no presentan la anomalía negativa de $\mathrm{Sr}$, la cual en las sucesiones expuestas en Charcas, Aramberri y Valle de Huizachal nos estaría indicando un origen por cristalización fraccionada, ya que el Sr presenta una fuerte afinidad con la plagioclasa. Esta idea parece ser consistente con las características petrográficas observadas en las muestras de la sucesión volcánica de Charcas, para las cuales su mineralogía se puede resumir de la siguiente manera: plagioclasa, minerales máficos, óxidos de hierro, escaso cuarzo y minerales arcillosos.
La edad de cristalización de una riodacita de la parte media de la sucesión volcánica de Charcas, San Luis Potosí, ha sido establecida en el presente estudio. El método geocronológico U-Pb en circón indica una edad absoluta de $179 \pm 1 \mathrm{Ma}$, que corresponde a la parte superior del Jurásico Inferior (Toarciano; Figura 13). Así, esta roca se puede correlacionar con las riolitas expuestas en el Cañón Ojo de Agua en la Sierra de Catorce, San Luis Potosí (174 $\mathrm{Ma}, \mathrm{U}-\mathrm{Pb}$ en circón; Barboza-Gudiño et al., 2004). Sin embargo, la riodacita de Charcas es más antigua que la riolita o pórfido riolítico de Caopas, al norte de Zacatecas (158 Ma, U-Pb en circón; Jones et al., 1995), pero considerablemente más joven que las riolitas y rocas piroclásticas del valle de Huizachal, Tamaulipas, a las cuales se les ha asignado una edad de $189 \mathrm{Ma}$ (Fastowsky et al., 2005). Recientemente, Rubio-Cisneros y Lawton (2011) han sugerido que el magmatismo de arco de la Formación Nazas en esta última localidad tuvo lugar en el intervalo 199-164 Ma. Dentro de este intervalo también se encuentran las dataciones reportadas para las rocas volcanoclásticas de Aramberri, Nuevo León (193 Ma, U-Pb en circón; Barboza-Gudiño et al., 2008) y en las riolitas de Villa Juárez, Durango (195 $\mathrm{Ma},{ }^{40} \mathrm{Ar} / \mathrm{Ar}^{39}$ en plagioclasa; Bartolini y Spell, 1997).

De lo anterior se puede establecer que la sucesión volcánica expuesta en el área de Charcas y las secuencias volcánicas aflorantes en el noreste de México, aunque con edades absolutas que varían en un intervalo entre 200 Ma y $156 \mathrm{Ma}$ (Figura 13), son comparables y estarían relacionadas 


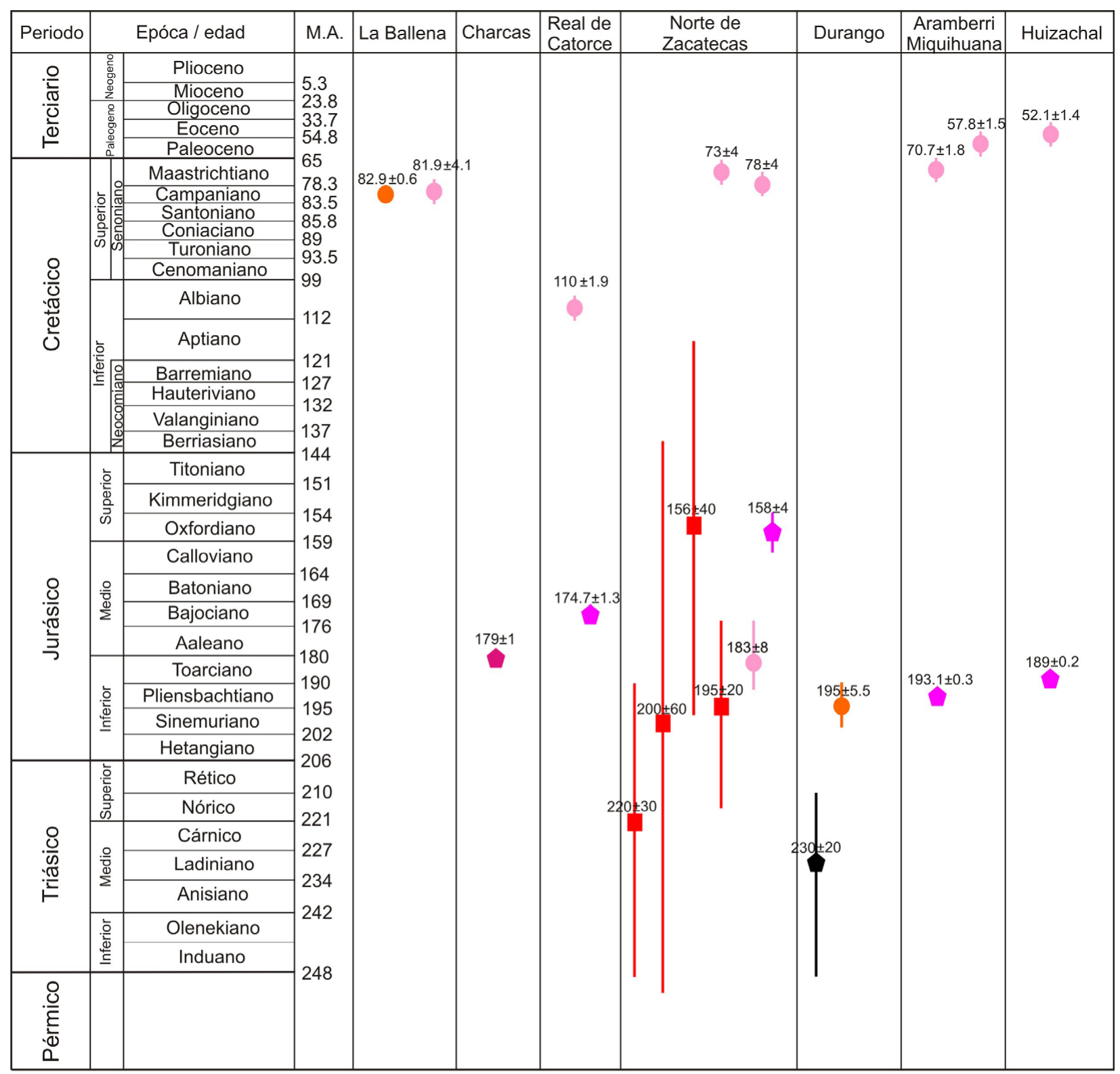

Rb-Sr Fries y Rincón-Orta (1967)

Pb-a Pantoja-Alor (1972)

U-Pb en circones, Jones et al., 1995

Barboza-Gudiño et al., 2004, 2008;

Fastowsky et al., 2005
K-Ar López-Infanzón, 1986;

Bartolini, 1998; Fastowsky et al., 2005;

Barboza-Gudiño et al., 1999, 2008

Ar-Ar Bartolini y Spell, 1997; Bartolini, 1998

Este trabajo

Figura 13. Edades absolutas de las unidades volcánicas pre-oxfordianas (a partir del Triásico Medio) del centro y noreste de México. Las dataciones isotópicas obtenidas mediante los métodos $\mathrm{K} / \mathrm{Ar}$ y $\mathrm{Ar} / \mathrm{Ar}$ en su mayoría reflejan sólo edades de recalentamiento, las cuales coinciden de manera general con la deformación larámidica.

genéticamente al proceso de subducción que tuvo lugar durante el Jurásico Temprano a Medio, a lo largo de la margen paleopacífica de Norteamérica, o bien de Pangea al tiempo de su fragmentación.

\section{Conclusiones}

La sucesión volcánica expuesta en el área de Charcas, San Luis Potosí, está constituida principalmente por rocas de composición intermedia a félsica, a manera de flujos piroclásticos en su mayoría, así como flujos de 
lava y brechas volcánicas. Es correlacionable en posición estratigráfica con las sucesiones asociadas al arco volcánico del Jurásico Inferior (Formación Nazas), expuestas en otras áreas del centro-norte y noreste de México. Además, la edad absoluta de las rocas volcánicas de Charcas (sección arroyo San Antonio; geocronología U-Pb en circón, $\mathrm{n}=19,179$ $\pm 1 \mathrm{Ma}$, Toarciano) queda comprendida dentro del período de la actividad magmática de dicho arco.

La geoquímica de la sucesión volcánica indica composiciones félsicas (riodacita y riolita) relacionadas a magmatismo de subducción del denominado Arco Nazas, aunque en algunos casos la afinidad tectónica no es clara. La ubicación de los afloramientos de rocas volcánicas jurásicas en la zona de Charcas permite prolongar la traza de este arco desde la región del norte de Zacatecas y Durango hasta esta porción del centro-noreste de México, con un rumbo general noroeste-sureste, que sería teóricamente subparalelo a la antigua margen paleopacífica de Pangea.

\section{Agradecimientos}

Los autores agradecen al Dr. Victor Valencia por su apoyo durante la preparación y el análisis geocronológico $\mathrm{U}-\mathrm{Pb}$ en circón. Se agradece a los árbitros Timothy $\mathrm{F}$. Lawton y Alexander Iriondo sus críticas constructivas y sugerencias, las cuales han permitido mejorar notablemente el escrito final.

\section{Referencias}

Barboza-Gudiño, J.R., Tristán-González, M., Torres-Hernández, J.R., 1998, The Late Triassic-Early Jurassic active continental margin of western North America in northeastern México: Geofísica Internacional, 37, 283-292.

Barboza-Gudiño, J.R., Tristán-González, M., Torres-Hernández, J.R., 1999, Tectonic setting of pre-Oxfordian units from central and northeastern Mexico: A review, en Bartolini, C., Wilson, J.L., Lawton, T.F. (eds.), Mesozoic Sedimentary and Tectonic History of North-Central Mexico: Boulder, Colorado, Geological Society of America, Special Paper 340, 197-210.

Barboza-Gudiño, J.R., Hoppe, M., Gómez-Anguiano, M., MartínezMacías, P.R., 2004, Aportaciones para la interpretación estratigráfica y estructural de la porción noroccidental de la Sierra de Catorce, San Luis Potosí, México: Revista Mexicana de Ciencias Geológicas, 21, 299-319.

Barboza-Gudiño, J.R., Orozco-Esquivel, M.T., Gómez-Anguiano, M., Zavala-Monsiváis, A., 2008, The Early Mesozoic volcanic arc of western North America in northeastern Mexico: Journal of South American Earth Sciences, 25, 49-63.

Barboza-Gudiño, J.R., Zavala-Monsiváis, A., Venegas-Rodriguez, G., Barajas-Nigoche, L.D., 2010, Late Triassic stratigraphy and facies from northeastern Mexico: Tectonic setting and provenance: Geosphere, 6, 621-640.

Bartolini, C., 1998, Stratigraphy, geochronology, geochemistry and tectonic setting of the Mesozoic Nazas Formation, north-central Mexico: El Paso, Texas, University of Texas, tesis doctoral, $558 \mathrm{p}$.

Bartolini, C., Spell, T., 1997, An Early Jurassic age (40 Ar/39Ar) for the Nazas Formation at the Cañada Villa Juárez, northeastern Durango, México (resumen), en Geological Society of America, South-Central
Section, 31st annual meeting, University of Texas, El Paso, Texas, Geological Society of America, Abstracts with Programs, 29(2), 3.

Bartolini, C., Lang, H., Stinnesbeck, W., 1999, Volcanic rock outcrops in Nuevo León, Tamaulipas and San Luis Potosí, Mexico: Remnants of the Permian-Early Triassic magmatic arc?, en Bartolini, C., Wilson, J.L., Lawton, T.F. (eds.), Mesozoic Sedimentary and Tectonic History of North-Central Mexico: Boulder, Colorado, Geological Society of America, Special Paper 340, 347-356.

Bartolini, C., Lang, H., Spell, T., 2003, Geochronology, geochemistry, and tectonic setting of the Mesozoic Nazas arc in north-central Mexico, and its continuation to north South America, en Bartolini, C., Buffler, R.T., Blickwede, J.F. (eds.), The Circum Golf of Mexico and the Caribbean:Hydrocarbon habitats, basin formation and plate tectonics: Tulsa, Oklahoma, American Association of Petroleum Geologists,memoir 79, 427-461.

Burckhardt, C., 1930, Étude Synthétique sur le Mésozoique Mexicain: Mémoire de la Sociéte Paléontologique Suisse, 49-50, 1-280.

Cantú-Chapa, A., 1969, Una nueva localidad del Triásico Superior marino en México: Revista del Instituto Mexicano del Petróleo, 1, 71-72.

Carrillo-Bravo, J., 1971, La Plataforma Valles-San Luis Potosí: Boletín de la Asociación Mexicana de Geólogos Petroleros, 23, 1-6.

Cuevas-Pérez, E., 1985, Geologie des altered Mesozoikums in Zacatecas und San Luis Potosí, México: Marburgo, Alemania, Universidad de Marburgo, tesis doctoral, $190 \mathrm{p}$.

Dickinson, W.R., Lawton, T.F., 2001, Carboniferous to Cretaceous assembly and fragmentation of Mexico: Geological Society of America Bulletin, 113, 1142-1160.

Eurachen working Group, 1998, The Fitness for Purpose of Analytical Methods: A Laboratory Guide to Method Validation and Related Topics, 0-948926-12-0, $61 \mathrm{p}$.

Fastowsky, D.E., Hermes, O.D., Strater, N.H., Bowring, S.A., Clark, J.M., Montellano, M., Hernández, R.R., 2005, Pre-Late Jurassic, fossilbearing volcanic and sedimentary red beds of Huizachal Canyon, Tamaulipas, Mexico, en Anderson, T.H., Nourse, J.A., McKee, J.W., Steiner, M.B. (eds.): Boulder, Colorado, Geological Society of America, Special Paper 393, 401-426.

Floyd, P.A., Winchester, J.A., 1978, Identification and discrimination of altered and metamorphosed volcanic rocks using immobile elements: Chemical Geology, 21, 291-306.

Fries, C., Rincón-Orta, C., 1967, Nuevas aportaciones geocronológicas y técnicas empleadas en el laboratorio de Geocronometría: Boletín del Instituto de Geología, Universidad Nacional Autónoma de México, 73, 57-133.

García-Obregón, R., 2007, Relaciones entre el Vulcanismo y la Sedimentación ContinentalDurante el Mesozoico Temprano en el Valle de Huizachal, Tamaulipas, México: Linares, Nuevo León, Facultad de Ciencias de la Tierra, Universidad Autónoma de Nuevo León, tesis de licenciatura, 137 p.

Gehrels, G.E., Valencia, V.A., Ruiz, J., 2008, Enhanced precision, accuracy, efficiency, and spatial resolution of $\mathrm{U}-\mathrm{Pb}$ ages by laser ablation-multicollector-inductively coupled plasma-mass spectrometry: Geochemistry Geophysics Geosystems, 9, Q03017, doi: 10.1029/2007GC001805.

Godínez-Urban, A., Lawton, T.F., Molina-Garza, R.S., Iriondo, A., Weber, B., and López-Martínez, M., 2011, Jurassic volcanic and sedimentary rocks of La Silla and Todos Santos Formations, Chiapas: Record of Nazas arc magmatism and rift-basin formation prior to opening of the Gulf of Mexico: Geosphere, 7, 121-144.

Gómez-Anguiano, M., 2001, Cartografía geológica del área de San Juan de Matanzas en la porción noroccidental de la Sierra de Catorce, San Luis Potosí y correlación estratigráfica y geoquímica de rocas volcanogénicas pre-Cretácicas del noreste de México: Linares, Nuevo León, México,Facultad de Ciencias de la Tierra,Universidad Autónoma de Nuevo León, tesis de maestría, 164 p.

Hoppe, M., Barboza-Gudiño, J.R., Schulz, H.M., 2002, Late Triassic submarine fan deposits in northwestern San Luis Potosi, Mexico lithology, facies and diagenesis:Neues Jahrbuch für Geologie und Paläontologie Abhandlungen, 12,705-724. 
Imlay, R.W., 1936, Evolution of the Coahuila Peninsula, Mexico, part IV, Geology of the western part of the Sierra de Parras: Geological Society of America Bulletin,47, 1091-1152.

Jones, N.W., McKee, J.W., Anderson, T.H., Silver, L.T., 1995, Jurassic volcanic rocks in northeastern Mexico: A possible remnant of a Cordilleran magmatic arc, en Jaques-Ayala, C., Gonzalez-León, C.M., Roldán Quintana, J. (eds.), Studies on the Mesozoic of Sonora and Adjacent Areas: Boulder, Colorado, Geological Society of America, Special Paper 301, 179-190.

López-Infanzón, M., 1986, Estudio petrogenético de las rocas ígneas en las Formaciones Huizachal y Nazas: Boletín de la Sociedad Geológica Mexicana, 47(2), 1-42.

Lozano, R., Bernal, J.P. 2005, Characterization of a new set of eight geochemical reference materials for XRF major and trace element analysis: Revista Mexicana de Ciencias Geológicas, 22, 329-344.

Martínez-Pérez, J., 1972, Exploración geológica del área El Estribo-San Francisco, San Luis Potosí: Boletín de la Asociación Mexicana de Geólogos Petroleros, 24, 327-402.

Mixon, R.B., 1963, Geology of the Huizachal Redbeds, Sierra Madre Oriental, Mexico: Baton Rouge, Estados Unidos, Louisiana State University, tesis doctoral, $97 \mathrm{p}$.

Mori, L., Gómez-Tuena, A., Cai, Y., Goldstein, S. L., 2007, Effects of prolonged flat subduction on the Miocene magmatic record of the central Trans-Mexican Volcanic Belt: Chemical Geology, 244, 452-473.

Mutti, E., Ricci-Lucchi, F., 1972, Le torbiditi dell'Apennino settentrionale; introduzione all'analisi di facies: Memorie della Società Geologica Italiana, 11, 161-199.

Pantoja-Alor, J., 1972, La Formación Nazas del Levantamiento de Villa Juárez, Estado de Durango: (memoria) en Segunda Convención Nacional de la Sociedad Geológica Mexicana, Mazatlán, Sinaloa, México, Sociedad Geológica Mexicana, 25-31.

Pearce, J.A., Harris, N.B.W., Tindle, A.G., 1984, Trace element discrimination diagrams for the tectonic interpretation of granitic rocks: Journal of Petrology, 25, 956-983.

Rollinson, H.R., 1993, Using Geochemical Data: evaluation, presentation, interpretation:Harlow, Essex, Reino Unido, Longman Scientific \& Technical, $352 \mathrm{p}$.

Rubio-Cisneros, I.I., Lawton, T.F., 2011, Detrital zircon U-Pb ages of sandstones in continental red beds at Valle de Huizachal, Tamaulipas, NE Mexico: Record of Early-Middle Jurassic arc volcanism and transition to crustal extension: Geosphere, 7, 159-170.

Silva-Romo, G., Arellano-Gil, J., Mendoza-Rosales, C., Nieto-Obregón, J., 2000, A submarine fan in the Mesa Central, Mexico: Journal of South American Earth Sciences, 13, 429-442.

Sun, S.S., McDonough, W.F., 1989, Chemical and isotopic systematics of oceanic basalts: implications for mantle composition and processes, en Saunders, A.D., Norry, M.J. (eds.), Magmatism in the Ocean Basins: Geological Society Special Publication, 42, 313-345.
Tristán-González, M., Torres-Hernández, J.R., 1991, Geología de la Sierra de Charcas, Estado de San Luis Potosí: (memoria) en Convención sobre la evolución geológica de México. Pachuca, Hidalgo, México: Instituto de Geología, Universidad Nacional Autónoma de México; Instituto de Investigaciones en Ciencias de la Tierra, Universidad Autónoma de Hidalgo; Sociedad Mexicana de Mineralogía, A. C., Subsecretaría de Educación Superior e Investigación Científica, Secretaría de Educación Pública, 221-223.

Tristán-González, M., Torres-Hernández, J.R., 1992, Cartografía Geológica 1:50000 de la Hoja Charcas, Estado de San Luis Potosí: San Luis Potosí, México,Instituto de Geología, Universidad Autónoma de San Luis Potosí, Folleto Técnico 115, 94 p.

Tristán-González, M., Torres-Hernández, J.R., 1994, Geología de la Sierra de Charcas, Estado de San Luis Potosí, México: Revista Mexicana de Ciencias Geológicas, 11, 117-138.

Verma, S.K., Pandarinath, K., Verma, S.P., 2012, Statistical evaluation of tectonomagmatic discrimination diagrams for granitic rocks and proposal of new discriminant-function-based multi-dimensional diagrams for acid rocks: International Geology Review, 54, 325-347, doi: $10.1080 / 00206814.2010 .543784$.

Verma, S.P., Rodríguez-Ríos, R., González-Ramírez, R., 2010, Statistical evaluation of classification diagrams for altered igneous rocks: Turkish Journal of Earth Sciences, 19, 239-265.

White, W.M., 2005. Geochemistry (libro electrónico en línea): Baltimore, EE.UU., Johns-Hopkins University Press, disponible en $<$ www. imwa.info/white-geochemistry.html $>$, consultado 30 de septiembre de 2012.

Wilson, M., 1989, Igneous Petrogenesis: Londres, Unwin Hyman, 466 p.

Winchester, J.A., Floyd, P.A., 1977, Geochemical discrimination of different magma series and their differentiation products using immobile elements: Chemical Geology, 20, 325-343.

Wood, D.A., 1980, The application of a Th-Hf-Ta diagram to problems of tectonomagmatic classification and to establishing the nature of crustal contamination of basaltic lavas of the British Tertiary volcanic province: Earth and Planetary Science Letters, 50, 11-30.

Manuscrito recibido: Junio 22, 2010.

Manuscrito corregido recibido: Mayo 5, 2011.

Manuscrito aceptado: Junio 2, 2011. 